\title{
Belirsizlik Altında Üretim Planlaması Problemi için Robust Eniyileme Modeli
}

\author{
Pembe GÜÇLÜ*, Ali ÖZDEMİR**
}

öz

İşletmelerin içinde bulundukları şartlar oldukça hızlı bir şekilde değişmektedir. Planlama yapılırken değişimin doğurduğu belirsizliği hesaba katmak adeta bir kural haline gelmiştir. Belirsizliği ele alma yöntemlerinden olan robust eniyileme teknikleri, değişen koşullara daha az duyarlı sonuçlar üreten modellerin oluşturulmasını sağlamaktadır. Üretim planlaması en basit anlamda hangi üründen, ne zaman, ne kadar üretileceğine karar verilmesidir. Üretim planlama problemlerinin modellenmesi ve çözümü üretim sürecinin, ele alınan parametrelerin ve değişkenlerin yapısına bağlı olarak farklılık göstermektedir. Bu çalışmada parametre ve talep belirsizliği altında, kapasite kısıtlı iki aşamalı, çok ürünlü üretim planlaması problemi için eniyileme modelinin oluşturulması ve çözülmesi amaçlanmıştır. Bu amaçla İzmir'de faaliyet gösteren bir tekstil firmasının üretim planlama problemi modellenerek çözülmüş, robust modelin sonuçları ile deterministik senaryoların sonuçları karşılaştırılmıştır. Robust yöntem, daha yüksek maliyetli ancak gelecekte karşılaşılabilecek farklı senaryoların çoğunluğunda büyük ölçüde olurlu ve optimale yakın sonuçlar verecek, sağlam bir üretim planı sunmuştur.

Anahtar Kelimeler: Robust Eniyileme, Üretim Planlamas1, Belirsizlik

JEL Sinıflandırması: M11, C61

\section{Robust Optimization Model for Production Planning Problem under Uncertainty}

\begin{abstract}
Conditions of businesses change very quickly. To take into account the uncertainty engendered by changes has become almost a rule while planning. Robust optimization techniques that are methods of handling uncertainty ensure to produce less sensitive results to changing conditions. Production planning, is to decide from which product, when and how much will be produced, with a most basic definition. Modeling and solution of the Production planning problems changes depending on structure of the production processes, parameters and variables. In this paper, it is aimed to generate and apply scenario based robust optimization model for capacitated two-stage multi-product production planning problem under parameter and demand uncertainty. With this purpose, production planning problem of a textile company that operate in İzmir has been modeled and solved, then deterministic scenarios' and robust method's results have been compared. Robust method has provided a production plan that has higher cost but, will result close to feasible and optimal for most of the different scenarios in the future.
\end{abstract}

Keywords: Robust Optimization, Production Planning, Uncertainty

JEL Classification: M11, C61

Geliş Tarihi / Received: 13.06.2016 Kabul Tarihi / Accepted: 31.10.2016

\footnotetext{
* Arş. Grv. Dr., Çankırı Karatekin Üniversitesi, İ̈BF, İşletme Bölümü, pembeguclu@karatekin.edu.tr

** Prof. Dr., Dokuz Eylül Üniversitesi, İ̈BF, İşletme Bölümü, ali.ozdemir@ deu.edu.tr
} 


\section{GİRIŞ}

İşletmelerin içinde bulundukları çevre koşullarının hızlı bir şekilde değişmesi ihtiyaçlarında ve planlarında sık sık değişimlere neden olmaktadır. Giderek çetinleşen rekabet ortamında işletmeler, yaşamlarını ve faaliyetlerini sürdürebilmek için proaktif ve çevik olmak zorundadır. $\mathrm{Bu}$ zorunluluk hızlı harekete geçmeyi gerektirdiği gibi, planlamaların da belirsizliklerin göz önüne alınarak yapılmasını gerektirmektedir.

İşletmelerde müşteri taleplerinin doğru bir şekilde, yerinde ve zamanında karşılanması için üretim planlaması hayati önem taşımaktadır. En temel anlamda üretim planlaması hangi üründen, ne kadar, ne zaman üretileceğinin belirlenmesine yönelik çalışmalardan oluşur. Üretim planlaması, dinamik ve belirsiz koşulların işletmelerde en çok etkilediği alanlardan birisidir. Bu durumda planlamanın talepte, süreçlerde, ekonomik-sosyal ve siyasal çevre faktörlerinde meydana gelebilecek, öngörülebilen veya öngörülemeyen belirsizlikler göz önünde bulundurularak yapılması, işletmeleri rakipleri arasında bir adım öne çıkaracaktır.

Gerçek uygulamalarda sistem dinamizminden dolayı çoğu zaman veriler doğru bir şekilde ölçümlenemeyebilir, tahminler gerçeği yansıtmayabilir veya uygulamada hatalar yapılabilir. Bu durumda elde edilen optimal çözümler kararları yanlış yönlendirebilir. Diğer yandan değişimin ortasında bir sürecin tam doğru olarak işlemesi ve optimal politikanın net bir şekilde uygulanarak en iyinin elde edilmesi ütopik bir düşüncedir. Gerçekleşecek koşullara göre planların sürekli güncellenmesindense uzun dönemli, proaktif planlar yapılarak ortaya çıkabilecek her duruma karşı hazırlıklı olmak gerekmektedir. Bu gereklilik robust modellemenin doğmasına ve yaygınlaşmasına neden olmuştur.

Robust eniyileme, belirsizliği matematiksel modelin içine dahil ederek, işletmelerin planlama döneminde karşılaşabileceği farklı koşulların bir çoğunda makul, belirsizliğe daha az duyarlı sonuçlar elde edilmesini sağlayan bir yöntem olarak tanımlanabilir. Gerçek hayat uygulamalarında karşılaşılan belirsizlik altındaki problemlerin mantığına yakın olması ve çözüm kolaylığı sağlaması gibi avantajları nedeniyle robust eniyileme konusunda yapılan çalışmaların son yıllarda hızla arttığı görülmektedir.

$\mathrm{Bu}$ çalışmada belirsiz talep ve girdi fiyatı koşullarında kapasite kısıtlı, çok aşamalı, çok ürünlü üretim planlama problemini modellemek ve eniyilemesini sağlamak amaciyla robust eniyileme modeli oluşturulmuş ve çözümü aranmıştır. Bu amaçla literatür taraması bölümünde robust eniyileme ile ilgili genel bilgiler verildikten sonra üretim planlamasında robust eniyileme uygulamaları ile ilgili yapılmış olan çalışmalara değinilmiştir. Ardından yöntem kısmında problemin modellemesinde kullanılan robust eniyileme tekniği tanıtılmış, problem tanımlanmış ve model oluşturulmuştur. Oluşturulan model çözülerek sonuçları bulgular bölümünde raporlanmıştır. Son bölümde ise model ve sonuçlar değerlendirilmiş, gelecek çalışmalar için önerilere yer verilmiştir.

\section{ROBUST ENIYILEME}

Eniyileme problemlerinde karar ortamındaki belirsizlikler bu güne kadar duyarlılık analizleri, stokastik programlama, bulanık mantık gibi tekniklerle değerlendirilmiştir. Duyarlılık analizinde parametrelerin sabit değerleri ile problem çözülmekte ve küçük oynamalardan en iyi çözümün nasıl etkilendiği görülmektedir. Uygulaması nispeten kolay olan teknik, post mortem bir yaklaşımdır. Belirsizlik altında kullanılan yöntemlerinden biri olan bulanık programlama, veriler hakkında yeterli bilgi olmadığı durumlarda belirsizlik ile ilgili kişisel yargıların üyelik fonksiyonları sayesinde eniyileme modeline dahil edilebilmesine olanak sağlar. Belirsizliği çözüm sürecine dahil etmesi açısında proaktif olsa da elde edilen durulaştırılmış sonuçlar karar vericiye hareket alanı ile ilgili bilgi vermemektedir. Olasılıksal (stokastik) programlama, belirsiz 
verilerin önceden tanımlanmış bir olasılık dağılımına uygun olduğu durumlarda kullanılan bir yöntemdir. Olasılıksal programlama da proaktif bir tekniktir, ancak verilerin olasılık dağılımının doğru bir şekilde tespit edilebilmesi için çok fazla veriye gereksinim duyulmaktadır. Ayrıca olasılıklı eniyileme problemlerinin çözümü ile ilgi de zorluklar yaşanmaktadır. Robust eniyileme ise problem parametrelerinin olasılıklı olmaktan ziyade deterministik ve küme tabanlı olduğu durumlarda kullanılır. Robust eniyileme modellerinin avantajlı yanlarından biri de eşdeğer modeller yazılarak, modelin çözülebilirliğinin kolaylaştırılabilmesidir.

Eniyilemede, veri belirsizliğinin nominal çözümün kalitesini büyük ölçüde etkilediği durumları tespit edebilecek ve bu gibi durumlarda veri belirsizliğine daha az duyarlı sonuçlar üretebilecek proaktif yaklaşıma ihtiyaç vardır (Ben-Tal vd., 2009; Sitompul ve Aghezzaf, 2008). Robust model ile verilerdeki belirsizlik model içine dahil edilir ve sağlam (robust) sonuçlar elde edilir. "Sağlamlık (Robustness) Yaklaşımı”nın amacı, önceden belirlenmiş bir planlama döneminde muhtemel tüm girdi verisi senaryolarında makul amaç değeri verebilecek kararlar üretmektir (Kouvelis ve Yu, 1997).

Bilim ve mühendislik için robust eniyileme, yeni bir konu sayılmaktadır ve robust kontrol ile yakından ilişkilidir. Robust eniyileme ile robust kontrol arasında ciddi benzerlikler bulunmakta, hatta robust eniyilemenin gelişimini sağlayan nedenler robust kontrol çevrelerinden gelmektedir. Ancak robust eniyileme, özellikle algoritma, geometri ve çözülebilirlik gibi geleneksel eniyilemenin teorik konularına, modelleme gücüne ve yapısal sonuçlara odaklanan ayrı bir alandır (Bertsimas vd., 2011).

Robust yaklaşımın eniyileme literatürüne, Soyster'in (1973) belirsiz verilerle doğrusal programlama problemini ele alması ile girdiği söylenebilir. Soyster, dış bükey bir kümeye ait olan belirsiz parametrelerin her durumu için olurlu bir çözüm üreten, korumacı bir model ortaya koymuştur. Soyster'in ardından robust eniyileme uygulamaları Mulvey ve arkadaşlarının 1995 yılında yaptıkları çalışma ile yaygınlaşmaya başlamıştır. Bu çalışmada yazarlar senaryo tabanlı doğrusal olmayan olasılıksal programlama yapısında bir robust eniyileme modeli önerisinde bulunmuşlardır. Model, hedef programlama ile senaryo tabanlı eniyilemeyi entegre ederek daha sonraları literatürde yaygın olarak kullanılan robust eniyileme modellerinden olmuştur. Bu temel çalışmaların ardından rağbet gören konu ile ilgili farklı alanlarda genel kabul gören çeşitli modeller geliştirilmiştir (Kouvelis ve Yu, 1997; Ben-Tal ve Nemirovski, 1998; Yu ve Li, 2000; Bertsimas ve Sim, 2003).

Robust eniyileme modelleri belirsizliği ele alma yöntemlerine küme tabanlı ve senaryo tabanlı olmak üzere iki ana kategoride ele alınabilmektedir.. Küme tabanlı modellerde belirsiz veriler spesifik bir belirsizlik kümesi içinde kalmak şartıyla değişkenlik gösterir. Amaç, veri belirsizliğine karşı duyarsızlaşmış, verilerin belirsizlik kümesi çerçevesinde aldığı tüm değerlerde olurlu çözüm elde etmektir (Li vd., 2011). Belirsizlik kümesi elemanları spesifik bir dağılıma uygunluk göstermez. Belirsizlik kümesi genellikle kapalı konveks kümedir. Literatürde farklı belirsizlik kümeleri (kutu, elipsodal, polihedral,...) kullanılarak robust eniyileme modelleri oluşturulmuştur (Soyster, 1973; Ben-Tall ve Nomirovski, 1998; Bertsimas ve Sim, 2003).

Senaryo tabanlı modellerde gürültü faktörü içeren veya tamamlanmamış veri seti ile hazırlanmış senaryoları kullanarak beklenen maliyeti ve en iyi maliyetten sapmaları minimize etmeyi amaçlamaktadır. Bu açıdan bakıldığında olasılıklı eniyilemenin robust eniyilemenin özel bir türü olduğu söylenebilir. Senaryo tabanlı robust eniyilemede temel amaç sağlam bir sistem tasarımında sistem içinde makul maliyetlerde ortaya çıan belirsiz durumlara yeterli esneklik sağlayabilmektir. Senaryo eniyilemesi, belirsiz senaryolar kümesinden elde edilen en iyi çözümleri dengeleyen olurlu bir çözüm bulmaya çalışır (Kang ve Lansey, 2013). Mulvey vd.(1995), Yu ve Li (2000) ve Kouvelis ve Yu (1997), Janak vd. (2007), Delage ve Ye (2010)'nin oluşturdukları robust modeller seneryo tabanlı temel modeller olarak sayılabilir. 
Veri setinin büyük ve parametrelerin sürekli olduğu durumlarda genellikle küme tabanlı modeller kullanılırken; veri setinin küçük, parametrelerin kesikli olduğu durumlarda genellikle senaryo tabanlı modeller kullanılmaktadır.

Bir sonraki bölümde üretim planlamasında belirsizlik kaynakları hakkında bilgi verilerek belirsizlikleri robust modeller ile ele alan çalışmalaradan oluşan literatür taramasına yer verilmiştir.

\section{3. ÜRETIM PLANLAMASINDA BELIRSIZLIK VE ROBUST ENIYILEME}

Üretim planlaması gelecekteki üretim ve hizmet faaliyetlerinin düzeylerini ve limitlerini belirleyen bir fonksiyon olarak tanımlanabilir (Kobu, 2010: 455). Üretim-İşlemler Planlaması, belirli ürünlerin ya da hizmetlerin ilerideki üretimleri için gerekli tüm olanakların saptanması, sağlanmas1 ve düzenlenmesini kapsar (Demir ve Gümüşoğlu, 2009: 349). Üretim planlamanın amacı, planlama döneminde toplam üretim maliyetlerini minimize edecek, talepleri karşılayacak şekilde üretim miktarını belirlemektir (Özyörük ve Erol, 2000: 105).

Üretim planlama problemlerinde belirsizlikler temel olarak iki kategori altında incelenebilir; i) çevresel belirsizlik, ii) sistemsel belirsizlik. Üretim süreci dışındaki talep belirsizliği, tedarik ile ilgili belirsizlikler, maliyet belirsizlikleri gibi belirsizlik türleri çevresel kategoride yer alırken; üretim sürecinin kendi içinde ortaya çıkan verim belirsizliği, bekleme sürelerindeki belirsizlik, üretim kalitesindeki belirsizlik, üretim sürecindeki aksamalardan kaynaklanan belirsizlikler ise sistemsel kategoride ele alınmaktadır (Mula vd., 2006).

İşletmeler belirsizliklere karşı çeşitli uygulamalar geliştirmişlerdir. Çevresel ya da sistemsel şartlardaki değişimlere karşı güvenlik stoğu, esnek kapasite planlaması, geç teslim (backloging) planlaması kullanılan reaktif uygulamalar olarak sayılabilir. Diğer yandan rutin kontrollerin sıklaştırılması ile çeşitli noktalardaki (tahmin hataları, bekleme zamanı, verimlilik vb.) belirsizlikleri izleyerek belirsizliklerin karakteristiğini belirleyerek taktik planların belirsizlik unsurunu göze alarak oluşturulması ise proaktif uygulama olarak değerlendirilebilir. $\mathrm{Bu}$ aşamada kullanılan matematiksel modellemelerde sayılan belirsizlik türlerinden biri ya da bir kaçı stokastik programlama, bulanık mantık, simülasyon, sezgisel algoritmalar, yapay sinir ağları, genetik algoritmalar, markov karar süreçleri veya robust eniyileme teknikleri ile ele alınmıştır. Üretim planlama problemlerinde belirsizliğin yapısı ve belirsizliği olasılıksal, olabilirsel, sezgisel ve robust eniyileme dışındaki diğer yöntemlerle ele alan çalışmalar ile ilgili ayrınt1lı bilgi için Mula vd. (2006), Ayuso vd. (2007), Dolgui vd. (2010), Graves (2011), Aloulou vd. (2013)'nin çalışmaları incelenebilir.

Üretim planlama ve kontrol sorunları da robust eniyilemenin etkin bir şekilde kullanıldığı alanlardandır. Tablo 1'de üretim planlaması alanında yapılan robust eniyileme çalışmaları ele alınan belirsizlik türüne ve kullanılan robust modellere göre sınıflandırılmıştır. 
Tablo 1: Robust Üretim Planlaması Çalışmalarındaki Belirsizlik Kaynakları ve Kullanılan Modeller

\begin{tabular}{|c|c|c|}
\hline Referans & Belirsizlik & Kullanılan Robust Model \\
\hline Leung ve Wu (2004) & Maliyet parametreleri, Talep & Yu ve $\mathrm{Li}$ \\
\hline Raa ve Aghezzaf (2005), & Talep & Mulvey vd. \\
\hline Bertsimas ve Thiele (2006), & Maliyet Parametreleri, Talep & Bertsimas ve Sim \\
\hline Leung vd. (2007a) & Maliyet parametreleri, Talep & Yu ve $\mathrm{Li}$ \\
\hline Leung vd. (2007b) & Maliyet parametreleri, Talep & Yu ve $\mathrm{Li}$ \\
\hline Ben-Tal vd. (2009) & Talep & Ben-Tal ve Nemirovski \\
\hline Agghezzaf vd. (2010) & Talep & Mulvey vd \\
\hline Kanyalkar ve Adil (2010), & Talep & Yu ve $\mathrm{Li}$ \\
\hline Zanjani vd. (2010), & Hammadde kalitesi & Mulvey vd. \\
\hline Pan ve Nagi (2010) & Talep & Mulvey vd. \\
\hline Zhou (2010), & Kesinti (Makine bozulması) & Kouvelis ve $\mathrm{Yu}$ \\
\hline Wei vd. (2011), & Geri dönen ürün miktarı, talep & Bertsimas ve Sim \\
\hline Al-e-Hasem vd. (2011) & Maliyet parametreleri, Talep & Yu ve $\mathrm{Li}$ \\
\hline Alem ve Morabito (2012) & Maliyet parametreleri, talep & Bertsimas ve Sim \\
\hline Wang vd. (2012) & Üretim maliyetleri & Bertsimas ve Sim \\
\hline Latifoğlu vd. (2013), & Güç kesintisi & Ben-Tal ve Nemirovski \\
\hline Aouam ve Brahimi (2013) & Talep, teslim süresi & Bertsimas ve Sim \\
\hline Rahmani vd. (2013) & Maliyet parametreleri, Talep & Yu ve $\mathrm{Li}$ \\
\hline Lalmazloumian vd., (2013), & Maliyet Parametreleri, Talep & Yu ve $\mathrm{Li}$ \\
\hline Klabjan vd. (2013) & Moment belirsizliği & Delage ve Ye (2010) \\
\hline Mahmoudzadeh vd. (2013), & Talep ve iade miktarı & Bertsimas ve Sim \\
\hline Alvarez ve Vera (2014) & Teknoloji katsayısı & Betsimas ve Sim \\
\hline Solyalı (2014) & $\begin{array}{l}\text { Talep ve Müssteriden Geri Dönen } \\
\text { Ürün Miktarı }\end{array}$ & $\begin{array}{l}\text { Bertsimas ve Sim-Yeni } \\
\text { AARM(Affinely Adjustable Robust } \\
\text { Model) }\end{array}$ \\
\hline Ait-Alla vd. (2014) & Talep & Yu ve $\mathrm{Li}$ \\
\hline Ye vd. (2014) & Talep & Lin vd. (2004), Janak vd. (2007) \\
\hline Nikmanfor vd. (2015) & $\begin{array}{l}\text { Maliyet Parametreleri, Satı̧s } \\
\text { Fiyatı, Talep }\end{array}$ & Yu ve $\mathrm{Li}$ \\
\hline
\end{tabular}

Bir sonraki bölümde problemin çözümünde kullanılmış olan robust eniyileme tekniği ile ilgili bilgi verilerek problemin formülasyonu yapılmıştır.

\section{YÖNTEM}

$\mathrm{Bu}$ çalışmada veri sayısının azlığı nedeni ile senaryo tabanlı modelleme kullanılmıştır. Yu ve Li Modeli'nin, Mulvey vd.'nin robust modelinden daha anlaş1lır ve çözümünün kolay olması, Kouvelis ve Yu Modelleri’nin sadece en iyi çözüm değerinden sapmaları dikkate 
almasına karşılık hem en iyi çözüm değerinden sapmaları hem de olurluluktan verilebilecek ödünü göz önüne alan daha kapsamlı bir model olması tercih sebebi olmuştur.

\subsection{Robust Eniyileme Modeli}

Robust eniyileme alanında yapılan ilk çalışma Soyster (1973) sayılsa da "robust eniyileme" kavramı Mulvey ve arkadaşlarının 1995 yılında yapmış oldukları çalışma ile literatüre girmiştir. Çalışmada senaryo tabanlı doğrusal olmayan olasılıklı programlama modeli olarak iki temel robust model oluşturulmuştur. Modellerden ilki varyans temeline dayanırken, ikincisi fayda temellidir. Bu modellerde sağlamlık (robustness), model sağlamlığı ve çözüm sağlamlığı olmak üzere iki ayrı parça olarak ele alınmıştır. Model sağlamlığı, ortaya çıkabilecek bütün senaryoların sonuçlarının neredeyse hepsinin olurlu olması durumu olarak tanımlanırken, bütün senaryo sonuçlarının en iyi çözüm değerine yakın olması ise çözüm sağlamlığı olarak tanımlanmıştır.

Genel eniyileme modeli aşağıdaki gibi verilmiş olsun;

$$
\begin{aligned}
& \text { Min } c^{t} x+d^{t} y \quad x \in R^{n_{1}}, y \in R^{n_{2}} \\
& \text { s.t. } \\
& A x=b \\
& B x+C y=e \\
& x, y \geq 0
\end{aligned}
$$

Verilen eniyileme modelinde $x \in R^{n_{1}}$ tasarım değişkeni vektörü, $y \in R^{n_{2}}$ kontrol değişkeni vektörüdür. Birinci kısıt (2) katsayıları sabit ve gürültü içermeyen yapısal kısıt, ikinci kısıt (3) ise katsayıları gürültülü kontrol klsitıdır.

$\Omega=\{1,2,3, \ldots, S\}$ senaryo kümesi olmak üzere her bir $s \in \Omega \mathrm{r}$ senaryosunda kontrol kısıtındaki katsayılar, senaryonun ortaya çıkma ihtimalini gösteren sabit bir $p_{s}$ olasılı̆̆ 1 ile $\left\{d_{s}, B_{s}, C_{s}, e_{s}\right\}$ değerlerini alır $\left(\sum_{s=1}^{S} p_{s}=1\right)$.

Her senaryo $s \in \Omega$ olmak üzere $\left\{y_{1}, y_{2}, \ldots, y_{s}\right\}$, kontrol değişkenleri kümesi ve $\left\{z_{1}, z_{2}, \ldots, z_{s}\right\}$, s senaryosunda kontrol kısitlarının izin verdiği uygunsuzluk (infeasibility) ölçüsü olan hata vektörleri kümesi olmak üzere robust eniyileme modeli şu şekilde oluşturulabilir;

$$
\begin{array}{lc}
\text { Min } \sigma\left(x, y_{1}, y_{2}, \ldots, y_{s}\right)+\omega \rho\left(z_{1}, z_{2}, \ldots, z_{s}\right) \\
\text { s.t. } \\
\begin{array}{lc}
\text { Ax }=b & \\
B_{s} x+C_{s} y_{s}+z_{s}=e_{s} & \forall s \in \Omega \\
x \geq 0, y_{s} \geq 0 & \forall s \in \Omega
\end{array}
\end{array}
$$

Çoklu senaryolarda amaç fonksiyonu $\xi=c^{t} x+d^{t} y, \rho_{s}$ olasılıkla rassal değişken alan $\xi_{s}=c^{t} x+d_{s}^{t} y_{s}$ 'şeklini alır. Bütünleşik amaç fonksiyonunu uzatmamak için beklenen değer fonksiyonu $\sigma()=.\sum_{s \in \Omega} \rho_{s} \xi_{s}$ şeklinde modellenebilir. En kötü durum (worst case) analizinde model en büyük değeri enküçükler ve fonksiyon $\sigma()=.\operatorname{Max}_{s \in \Omega} \xi_{s}$ olur.

Amaç fonksiyonunun ikinci kısmı, bazı senaryolarda kontrol kısıtı ihlalini cezalandıran olurluluk (feasibility) ceza fonksiyonudur. Kontrol kısıtının ihlali, belirlenen bazı senaryolarda problemin çözümünün olursuz olduğu anlamına gelir. $\omega$ ağırlığı kullanılarak amaç fonksiyonunun birinci terimi ile ölçülen çözüm sağlamlığı ile ikinci terimi ile ölçülen model sağlamlığ1 arasındaki değişim (trade off) sağlanmış olur (Mulvey vd., 1995: 266). Örneğin $\omega=0$ ise model $\sigma($.$) terimini minimize edecek ve çözüm olursuz olacaktır. \omega$ 'ye yeterince büyük bir değer atandığında $\rho($.$) amaçta baskın olacak ve amaç daha yüksek bir maliyette$ gerçekleşecektir (Leung ve Wu, 2007). 
$\xi_{s}=c^{t} x+d_{s}^{t} y_{s}$ için yüksek varyans çıktının büyük ölçüde şüpheli olduğu anlamına gelir. Markowitz (1991)'in Ortalama/Varyans Modeli'nden yola çıkarak $\sigma($.$) İçin en uygun çözüm$ amaç fonksiyonunun ortalama değerine $\lambda$ defa varyans eklenerek şu şekilde elde edilir (Mulvey vd.,1995);

$$
\sigma\left(x, y_{1}, y_{2}, \ldots, y_{s}\right)=\sum_{s \in \Omega} p_{s} \xi_{s}+\lambda \sum_{s \in \Omega} p_{s}\left(\xi_{s}-\sum_{s^{\prime} \in \Omega} p_{s}^{\prime} \xi_{s^{\prime}}\right)^{2}
$$

Amaç fonksiyonun ikinci kısmı $\omega \rho\left(\mathrm{z}_{1}, \mathrm{z}_{2}, \ldots, \mathrm{z}_{\mathrm{s}}\right)=\omega \sum_{\mathrm{s} \in \Omega} \mathrm{p}_{\mathrm{s}} \mathrm{z}_{\mathrm{s}}$ şeklinde düzenlenirse robust eniyileme modeli şu şekli alır;

$$
\begin{aligned}
& \operatorname{Min} \sum_{s \in \Omega} p_{s} \xi_{s}+\lambda \sum_{s \in \Omega} p_{s}\left(\xi_{s}-\sum_{s^{\prime} \in \Omega} p_{s}^{\prime} \xi_{s^{\prime}}\right)^{2}+\omega \sum_{s \in \Omega} p_{s} z_{s} \\
& \text { s.t. } \\
& A x=b \\
& B_{s} x+C_{s} y_{s}+z_{s}=e_{s} \quad \forall s \in \Omega \\
& x \geq 0, y_{s} \geq 0 \quad \forall s \in \Omega
\end{aligned}
$$

Modelde yer alan $\lambda \sum_{s \in \Omega} p_{s}\left(\xi_{s}-\sum_{s^{\prime} \in \Omega} p_{s}^{\prime} \xi_{s^{\prime}}\right)^{2}$ ifadesi çözüm sağlamllğ sağlarken $\omega \sum_{s \in \Omega} p_{s} z_{s}$ ifadesi model sağlamlığı sağlar.

Yu ve Li (2000), Mulvey vd.'nin önerdikleri modeli geliştirerek modeli olmayan yapıdan kurtarmışlar ve [2(senaryo sayısı+kontrol kısıtı sayısı)] 2n+2m kadar sapma değişkeni sayısını yarıya düşürmüşlerdir. Modelin yeni hali ile $N=2\left(S+\sum_{S=1}^{S} J_{S}\right)$ adet yeni değişken ile toplam $M=G+S+\sum_{S=1}^{S} J_{S}$ kısıt sayısı ile doğrusal programlama modeli oluşturulmuştur. Bu yaklaşım ile modellerin çözüm sonuçları aynı kalırken, değişken sayısı farklılaşarak problemin karmaşıklığı azaltılmıştır.

$$
\begin{aligned}
& \operatorname{Min} \sum_{s \in \Omega} p_{s} \xi_{s}+\lambda \sum_{s \in \Omega} p_{s}\left(\xi_{s}-\sum_{s^{\prime} \in \Omega} p_{s}^{\prime} \xi_{s^{\prime}}+2 \theta_{s}\right)+ \\
& \sum_{s \in \Omega} p_{s}\left(\sum_{j=1}^{J}\left(w_{s j}^{+} \quad\left(B_{s} x+C_{s} y_{s}-e_{s}+z_{s j}\right)+w_{s j}^{-} z_{s j}\right)\right. \\
& \text { s.t. } \\
& A x=b \\
& \left(\sum_{s^{\prime} \in \Omega} p_{s}^{\prime} \xi_{s^{\prime}}\right)-\left(\xi_{s}\right)-\theta_{s} \leq 0 \\
& e_{s}-B_{s} x-C_{s} y_{s}-z_{s j} \leq 0 \\
& x \geq 0, y_{s} \geq 0 \quad \forall s \in \Omega
\end{aligned}
$$

\subsection{Problem Tanımı ve Formülasyonu}

Çalışmada İzmir'de faaliyet gösteren bir tekstil işletmesinin üretim süreci için model uygulaması gerçekleştirilmiştir. İlgili işletmenin üretim süreci iki ana aşamadan oluşmaktadır. Aşamaların her birinde sıralı işlemlerin gerçekleștiği iş hatları yer almaktadır. Birinci aşamada yüksek basınç uygulayan merdanelerin bulunduğu kalender adı verilen özdeş iki iş hattında ara mamul üretimi gerçekleşmektedir. Kalender hattından rulolar halinde çıkan yarı mamul işlem görmek üzere ikinci aşamadaki rotagravür hattına alınmaktadır. Bu aşamada farklı desen kalıpları yardımıyla ilk aşamadan çıkan yarı mamul üzerine baskı işlemi yapılmaktadır. 
Firma, dört farklı marka altında beş yüzden farklı desende üretim yapmaktadır. Markalar, desenlerin benzer özelliklerine ve pazarlandıkları ülkelere göre oluşturulmuştur. $\mathrm{Bu}$ çalışmada dört farklı markadaki ürünler ana ürün ailesi olarak ele alınmıştır. Uygulama için altı aylık planlama ufku aylık periyotlara bölünmüştür.

Firma hammadde alımlarını dolar para birimiyle yaptığı için dolar kurundaki değişimlere bağlı olarak hammadde fiyatları belirsiz kabul edilmiş ve senaryolar bu doğrultuda oluşturulmuştur. Firmanın ürettiği nihai ürünün talebinde mevsimsellik olmadığı için ve dolar kurundaki belirsizlikle zaman bazında uygun bir şekilde ele alınabilmesi adına talep senaryoları geçmişteki üç farklı altı aylık dönem verilerinden faydalanarak oluşturulmuştur.

Belirsiz talep ve üretim ile belirlenen diğer kısıtlar altında robust parti büyüklüğü belirleme problemi formüle edilmiştir. Modelin yapısını anlamayı kolaylaştırması açısından karar değişkeni ve parametreler ile ilgili çeşitli notasyonların ve modelin varsayımlarının tanımlanması yararlı olacaktır.

\section{Varsayımlar}

- Nihai ürün talebi ve hammadde fiyatları belirsizdir.

- Talepteki ve hammadde fiyatlarındaki belirsizlik senaryolar ile ele alınmıştır.

- Planlama ufku (T) eşit planlama periyotlarına (t) ayrılmıştır.

- Talebin geç karşılanmasına izin verilmektedir.

- Üretimdeki bekleme yoktur.

- Nihai ürünler ürün ailesi olarak ele alınmıştır.

- Makine ayarının ürün ailesi değiştikçe yapılmaktadır. Ürün ailesi içindeki farklı ürünler için yapılan ayarlar göz ardı edilmiştir.

- Planlama ufkunun başında makineler spesifik bir ürünü üretmek üzere ayarlı değildir.

- Makinelerin üretim kapasiteleri daha önceden yapılan taktik planlar ile belirlenmiştir.

- Birim stoklama maliyetleri, talebi geç karşılama maliyeti, üretim maliyeti periyotlar arası farklıl1k göstermemektedir.

\section{Kisitlamalar}

- Gerçek net talep değerlerinin kullanılmasına firma yetkililerince sıcak bakılmaması üzerine talep verileri yuvarlanarak gerçek verilere yaklaşık olacak şekilde alınmıştır.

- Firma verilerinin ve ürün girdi karışımının net değerlerinin gizliliği adına üretimde kullanılan sekiz hammaddenin tümü yerine, karışımda oransal olarak en fazla kullanılan üç girdi modele dahil edilmiştir.

\section{Notasyon}

\section{Indisler}

$i \quad$ : Nihai ürün indeksi $(i=1, \ldots, N)$

$j:$ Ara mamül indeksi

$r$ : Hammadde indeksi $(r=1, \ldots, R)$

$t \quad$ : Zaman periyodu indeksi $(t=1, \ldots, T)$

\section{Parametreler}

$h_{i t} \quad: \quad t$ periyodunda $i$ ürününü için birim stoklama maliyeti

$h_{r t}: t$ periyodunda $r$ hammaddesi için birim stoklama maliyeti

$p c_{i t}: t$ periyodunda $i$ ürününün birim üretim maliyeti

$s c_{i t}: t$ periyodunda $i$ ürünü için üretime hazırlık (set up) maliyeti 
$s c_{j t}: \quad t$ periyodunda birinci üretim aşaması için üretime hazırlık (set up) maliyeti

$s t_{i}: i$ ürünü için üretime hazırlık (set up) süresi

$s t_{j} \quad: \quad$ yarı mamül için üretime hazırlık (set up) süresi

$b_{i t} \quad: \quad t$ periyodunda $i$ ürünü için birim geç teslim (back-order) maliyeti

$c_{r t}^{s} \quad: s$ senaryosunda $t$ periyodunda $r$ hammaddesi için birim satın alma maliyeti

$g_{\text {ir }} \quad:$ Gozinto faktörü (bir birim $i$ üretmek için kullanılan $r$ hammaddesi miktarı)

$d_{i t}^{S} \quad: \quad s$ senaryosunda $t$ periyodunda $i$ ürününün talep miktarı

$\theta_{i} \quad: \quad i$ ürününün birim kapasite kullanımı

$\theta_{j} \quad$ : Yarımamülün birim kapasite kullanımı

$I_{r t}^{\max }: \quad r$ hammaddesinden t periyodunda en fazla stoklama miktarı

$I_{t}^{\max }: t$ periyodunda stoklanabilecek en fazla nihai ürün miktarı

$I_{t}^{\min }: t$ periyodunda bulunması gereken en az nihai ürün stoku miktar1

$K_{t} \quad: \quad t$ periyodunda birinci aşamanın üretim kapasitesi

$R_{t} \quad: \quad t$ periyodunda ikinci aşamanın üretim kapasitesi

$\beta_{i t} \quad: \quad t$ periyodunda i ürününün karşılanamayan talep (backorder) oranı

$\lambda \quad$ : Çözüm varyansının katsayısı

$\omega \quad$ : Kontrol kisitından sapmaların ceza katsayısı

$p^{s} \quad: \quad s$ senaryosunun olasilı̆̆ 1

Sayılan parametrelere ilişkin işletme verileri Tablo 5, Tablo 6, Tablo 7 ve Tablo 8'de verilmiştir. Bunlara ek olarak nihai ürün üretiminde kullanılan birim yarımamul miktarının $\left(g_{i j}\right)$ her nihai ürün için $1 \mathrm{~m} / \mathrm{m}$ olduğu bilinmektedir.

Tablo 2: Yarı Mamül ve Nihai Ürün Bazında Parametre Verileri

\begin{tabular}{|c|c|c|c|c|c|c|c|}
\hline $\begin{array}{c}\text { Yarımamul/ } \\
\text { mamul }\end{array}$ & $\begin{array}{c}h \\
(\mathrm{TL} / \mathrm{m})\end{array}$ & $\begin{array}{c}p \\
(\mathrm{TL} / \mathrm{m})\end{array}$ & $\begin{array}{c}S \\
(\mathrm{TL})\end{array}$ & $\begin{array}{c}b \\
(\mathrm{TL} / \mathrm{m})\end{array}$ & $\begin{array}{c}s t \\
\text { (dk) }\end{array}$ & $\begin{array}{c}\theta \\
\mathrm{dk} / \mathrm{m}\end{array}$ & $\beta$ \\
\hline$j 1$ & - & - & 0.040 & - & 20 & 0.21 & \\
\hline$i 1$ & 0.135 & 0.660 & 0.033 & 1.4 & 20 & 0.13 & 0.25 \\
\hline$i 2$ & 0.135 & 0.660 & 0.032 & 1.3 & 20 & 0.13 & 0.25 \\
\hline$i 3$ & 0.135 & 0.660 & 0.035 & 1.2 & 20 & 0.13 & 0.25 \\
\hline$i 4$ & 0.135 & 0.660 & 0.036 & 1.5 & 20 & 0.13 & 0.10 \\
\hline \multicolumn{8}{|c|}{$\begin{array}{c}K_{t}=34,560 \mathrm{dk} / a y \\
R_{t}=34,560 \mathrm{dk} / a y \\
I_{t}^{\max }=300,000 \mathrm{~m} / \mathrm{ay} \\
I_{t}^{\min }=40,000 \mathrm{~m} / \mathrm{ay}\end{array}$} \\
\hline
\end{tabular}

Tablo 3: Hammaddelerle İlgili Parametre Verileri

\begin{tabular}{cccc}
\hline & $\begin{array}{c}g_{j r} \\
(\mathrm{~kg} / \mathrm{m})\end{array}$ & $\begin{array}{c}I_{r t}^{\max } \\
(\mathrm{m})\end{array}$ & $\begin{array}{c}h_{r t} \\
(\mathrm{TL} / \mathrm{kg})\end{array}$ \\
\hline$r_{1}$ & 2.15 & 67,000 & 0.013 \\
$r_{2}$ & 1.50 & 25,000 & 0.015 \\
$r_{3}$ & 10 & 400,000 & 0.020 \\
\hline
\end{tabular}


Tablo 4: Senaryolar Bazında Talep $\left(d_{i t}\right)$ Verileri

\begin{tabular}{ccrrrrrr}
\hline \multirow{2}{*}{ Mamül } & \multirow{2}{*}{ Senaryo } & \multicolumn{7}{c}{ Zaman Periyotları } \\
\cline { 2 - 8 } & 1 & \multicolumn{1}{c}{$\boldsymbol{t}_{\mathbf{1}}$} & \multicolumn{1}{c}{$\boldsymbol{t}_{\mathbf{2}}$} & \multicolumn{1}{c}{$\boldsymbol{t}_{\mathbf{3}}$} & \multicolumn{1}{c}{$\boldsymbol{t}_{\mathbf{4}}$} & \multicolumn{1}{c}{$\boldsymbol{t}_{\mathbf{5}}$} & \multicolumn{1}{c}{$\boldsymbol{t}_{\mathbf{6}}$} \\
\hline \multirow{3}{*}{$\boldsymbol{i}_{\mathbf{1}}$} & 2 & 25,000 & 20,000 & 25,000 & 16,000 & 8,500 & 10,000 \\
& 3 & 29,000 & 21,000 & 24,000 & 10,000 & 10,000 & 15,000 \\
\hline \multirow{3}{*}{$\boldsymbol{i}_{\mathbf{2}}$} & 1 & 8,000 & 6,000 & 15,000 & 10,000 & 3,500 & 4,800 \\
& 2 & 8,000 & 12,000 & 9,000 & 9,000 & 5,000 & 10,000 \\
& 3 & 12,000 & 9,500 & 14,500 & 8,000 & 4,000 & 11,000 \\
\hline \multirow{3}{*}{$\boldsymbol{i}_{\mathbf{3}}$} & 1 & 3,000 & 3,000 & 2,000 & 2,000 & 2,500 & 2,500 \\
& 2 & 5,000 & 6,000 & 4,000 & 3,000 & 2,500 & 4,000 \\
& 3 & 3,000 & 5,000 & 8,000 & 4,000 & 5,000 & 3,000 \\
\hline \multirow{3}{*}{$\boldsymbol{i}_{\mathbf{4}}$} & 1 & 100,000 & 100,000 & 150,000 & 100,000 & 50,000 & 60,000 \\
& 2 & 100,000 & 110,000 & 115,000 & 90,000 & 75,000 & 100,000 \\
& 3 & 90,000 & 120,000 & 112,000 & 150,000 & 100,000 & 80,000 \\
\hline
\end{tabular}

Tablo 5: Senaryolar Bazında Hammadde Fiyat $\left(c_{r t}\right)$ Verileri (TL/kg)

\begin{tabular}{cccccccc}
\hline \multirow{2}{*}{ Hammadde } & \multirow{2}{*}{ Senaryo } & \multicolumn{7}{c}{ Zaman Periyotları } \\
\cline { 2 - 7 } & & $\boldsymbol{t}_{\mathbf{1}}$ & $\boldsymbol{t}_{\mathbf{2}}$ & $\boldsymbol{t}_{\mathbf{3}}$ & $\boldsymbol{t}_{\mathbf{4}}$ & $\boldsymbol{t}_{\mathbf{5}}$ & $\boldsymbol{t}_{\mathbf{6}}$ \\
\hline \multirow{2}{*}{$\boldsymbol{r}_{\mathbf{1}}$} & 1 & 1.500 & 1.550 & 1.550 & 1.520 & 1.590 & 1.600 \\
& 2 & 1.176 & 1.208 & 1.224 & 1.192 & 1.232 & 1.256 \\
& 3 & 0.972 & 0.992 & 1.012 & 0.985 & 0.998 & 1.039 \\
\hline \multirow{2}{*}{$\boldsymbol{r}_{\mathbf{2}}$} & 1 & 0.278 & 0.287 & 0.287 & 0.281 & 0.294 & 0.296 \\
& 2 & 0.257 & 0.264 & 0.268 & 0.261 & 0.270 & 0.275 \\
& 3 & 0.247 & 0.252 & 0.257 & 0.250 & 0.253 & 0.264 \\
\hline \multirow{2}{*}{$\boldsymbol{r}_{\mathbf{3}}$} & 1 & 3.375 & 3.488 & 3.488 & 3.420 & 3.578 & 3.600 \\
& 2 & 3.175 & 3.262 & 3.305 & 3.218 & 3.326 & 3.391 \\
& 3 & 2.538 & 2.590 & 2.643 & 2.573 & 2.608 & 2.713 \\
\hline
\end{tabular}

\section{Karar Değişkenleri}

$X X_{i t}: \quad t$ periyodunda $i$ ürününün üretim miktarı

$X_{j t} \quad: \quad t$ periyodunda yarı mamul üretim miktarı

$B_{i t}^{S} \quad: \quad s$ senaryosunda $t$ periyodunda $i$ ürününü için backorder miktarı

$W_{r t}: t$ periyodunda $r$ hammaddesinden satın alınan miktar

$I_{i t}^{S} \quad: \quad s$ senaryosunda $t$ periyodunda $i$ ürünü stok miktarı

$I_{j t} \quad: \quad t$ periyodunda $j$ yarı mamülü stok miktarı

$I_{r t} \quad: \quad t$ periyodunda $r$ hammaddesi stok miktarı

$y_{i t} \quad: \quad t$ periyodunda $i$ ürünü için set up yapma durumu (set up yapıldıysa 1 , yapılmadıysa 0 değeri alır)

$y_{j t}$ : $t$ periyodunda $j$ yarı mamülü için set up yapma durumu (set up yapıldıysa 1, yapılmadıysa 0 değeri alır)

$\delta_{i t s}: \quad s$ senaryosunda $t$ periyodunda $i$ ürünü stok dengeleme kısıtından sapma miktarı

$\gamma^{s}: s$ senaryosunda amaç fonksiyonunun tüm senaryoların en iyi değerinden sapma miktar1

\section{Amaç Fonksiyonu}

Robust modelin amaç fonksiyonunun (19) ilk terimi senaryoların beklenen maliyetleri toplamını, ikinci terimi optimallikten sapmaların toplamını, üçüncü terimi ise doyurulmak zorunda olan kısitlardan sapmaların ceza maliyetleri toplamını ifade etmektedir. 


$$
\begin{gathered}
Z_{\text {min }}=\sum_{s=1}^{S} p^{s} T C^{s}+\lambda \sum_{s=1}^{S} p^{s}\left[\left(T C^{s}-\sum_{s=1}^{S} p^{s} T C^{s}\right)+2 \gamma^{s}\right] \\
+\omega \sum_{s=1}^{S} \sum_{t=1}^{T} \sum_{i=1}^{N} p^{s} \delta_{i t s} \\
T C^{s}=\sum_{i}^{N} \sum_{t}^{T}\left(h_{i t} I_{i t}^{S}+s c_{i t} y_{i t}+p c_{i t} X_{i t}+b_{i t} B_{i t}^{s}\right)+\sum_{j}^{J} \sum_{t}^{T}\left(s c_{j t} y_{j t}\right) \\
+\sum_{r}^{R} \sum_{i}^{N} \sum_{t}^{T} c_{r t}^{s} g_{i t} X_{i t}+\sum_{r}^{R} \sum_{t}^{T} h_{r t} I_{r t}
\end{gathered}
$$

Beklenen maliyet her bir senaryo için (20)'de yer alan eşitlik ile hesaplanır. $\mathrm{Bu}$ eşitlikte ilk terim doğrudan nihai ürünler için sırasıyla stoklama, üretim ayarı (set up), üretim ve geç teslim (backorder) maliyeti toplamından oluşmaktadır. İkinci terim ilk aşamanın makine ayar maliyeti, üçüncü terimi hammadde tedarik maliyetini, dördüncü ve son terimi ise toplam hammadde stoklama maliyetini ifade etmektedir. İlk aşamanın üretim maliyeti, firma tarafından nihai ürünün üretim maliyeti içinde hesaplandığı ayrı bir maliyet kalemi olarak ele alınmamıştır.

\section{Kisitlar}

$$
\begin{aligned}
& T C^{s}-\sum_{s=1}^{S} p^{s} T C^{s}+\gamma^{s} \geq 0 \quad \forall s, \\
& I_{i, t-1}^{s}+X_{i t}+B_{i t}^{s}-B_{i, t-1}^{s}-I_{i, t}^{s}+\delta_{i t s}=d_{i, t}^{s} \quad s=1, \ldots, S, i=1, \ldots, N, t=1, \ldots, T \\
& I_{r t}=I_{r, t-1}+W_{r t}-\sum_{j=1}^{J} g_{j r} X_{j t} \quad r=1, \ldots, R, \quad t=1, \ldots, T \\
& I_{j t}=I_{j, t-1}+X_{j t}-\sum_{i=1}^{N} g_{i j} X X_{i t} \quad \quad j=1, \ldots, J, \quad t=1, \ldots, T \\
& I_{r t} \leq I_{r t}^{\max } \quad r=1, \ldots, R, \quad t=1, \ldots, T \\
& \sum_{i=1}^{n} I_{i, t}^{s} \leq I_{t}^{\max } \quad s=1, \ldots, S, \quad t=1, \ldots, T \\
& \sum_{i=1}^{n} I_{i, t}^{s} \geq I_{t}^{\min } \quad s=1, \ldots, S, \quad t=1, \ldots, T \\
& B_{i t}^{S} I_{i, t}^{s}=0 \quad s=1, \ldots, S, \ldots . i=1, \ldots, N, \quad t=1, \ldots, T \\
& B_{i t}^{S} \leq \beta_{i t} d_{i, t}^{S} \quad s=1, \ldots, S, \quad i=1, \ldots, N, \quad t=1, \ldots, T \\
& X_{j t} \theta_{j}+s t_{j t} y_{j t} \leq K_{t} \quad t=1, \ldots, T \\
& X_{j t} \theta_{j} \leq K_{t} y_{j t} \quad j=1, \ldots, J, \quad t=1, \ldots, T
\end{aligned}
$$




$$
\begin{aligned}
& \sum_{i}^{N}\left(\theta_{i} X X_{i t}+s t_{i} y_{i t}\right) \leq R_{t} \quad t=1, \ldots, T \\
& \theta_{i} X_{i t} \leq R_{t} y_{i t} \quad i=1, \ldots, N, \quad t=1, \ldots, T \\
& X X_{1 t}+X X_{4 t} \leq 120,000 \quad t=1, \ldots, T \\
& X X_{i t}, X_{j t}, I_{r t}, I_{j t}, I_{i t}^{S}, W_{r t}, B_{i t}^{s}, \theta_{j}, \theta_{, i}, \gamma^{s}, \delta_{i t s} \geq 0 \quad \forall r, j, i, t, s \\
& y_{j t}, y_{i t} \in\{0 ; 1\} \quad \forall j, i, t
\end{aligned}
$$

(21)'de yer alan kisıt senaryolar bazında optimal maliyetten sapmalara izin veren kisittır. Nihai ürün stok dengeleme kısıtında (22), dönem talebinin, önceki dönemin dönem sonu stok miktarı, ilgili dönemdeki üretim miktarı ve o dönemde karşılanamayan talep miktarı toplamından dönem sonu stok ve önceki dönemin karşılanamayan talebinin düşülmesi ile elde edilen kalana eşit olması gerektiği ifade edilmektedir. Stok dengeleme kısıtı belirsiz koşullar için sapma değişkeni eklenerek esnetilmiştir. (23)'de yer alan hammadde stok dengeleme kısıtı, dönem sonu hammadde stok miktarının, önceki dönemin dönem sonu stok miktarı ile ilgili dönemde satın alınan hammadde miktarının toplamından o dönemin üretiminde kullanılan miktarın düşülmesi ile hesaplandığını göstermektedir. Benzer hesaplama (24) de yer alan yarı mamül stok dengeleme kısıtı için de söz konusudur. (25) hammaddeler için, (26) ise nihai ürünler için en fazla stoklama miktarına ilişkin kısıtlarıdır. Birinci aşamada üretilen yarımamüller stoklama alanına taşınmadan ikinci üretim aşamasına alındığ yarımamül için stoklama kalemi bulunmamaktadır. (27)'de yer alan kısıt, firmanın güvenlik amacıyla her dönem elinde bulundurması gereken stok miktarını belirlemeye yöneliktir. (28), bir dönemde karşılanamayan talep durumunun ortaya çıkabilmesi için dönem sonuna stok kalmamış olması gerektiğini, başka bir deyişle, dönem sonuna stok bırakılabiliyorsa stok dışı kalma ihtimalinin olmayışını ifade etmektedir. Doğrusal yapıda olmayan kısıt "ise o zaman" kısıtı gibi düşünülerek doğrusallaştırılabilir. (29)'da yer alan kısıt ise karşılanamayan talep miktarının, ilgili ürünün o dönemdeki talebinin belirli bir oranından daha fazla olmaması gerektiğini göstermektedir. (30) ve (31) birinci üretim aşaması için süre bazlı kapasite kısıtları iken, (32) ve (33) ikinci aşama için kapasite kısıtlarıdır. Talep yoğunluğundan dolayı firma her dönemde birinci ve dördüncü üründen toplam 120,000 metreden fazla üretim yapmalıdır (34). Son olarak (35) karar değişkenleri için pozitiflik koşulunu oluştururken, (3.6) birinci ve ikinci aşamanın set up değişkenlerinin 0-1 tamsayı değerlerini alabileceğini göstermektedir.

Problemin tanımlanması ve formülasyonunun ardından bir sonraki bölümde çözüm sonuçları raporlanmıştır.

\section{BULGULAR}

Oluşturulan robust üretim planlaması modeli, GAMS 24.1.3 (General Algebraic Modeling System) programı içinde çalışan IBM ILOG CPLEX 12.5.1 yardımıyla çözülmüştür.

Robust modellemenin, sonuçlarının ve öneminin daha iyi anlaşılması açısından öncelikle farklı parametre ( $\lambda$ ve $\omega$ ) değerleri için robust modeller çözülerek sonuçlar analiz edilmiştir. Robust model parametrelerinden olan $\lambda$, modelde çözüm varyansının katsayısı olarak yer almakta ve bütün senaryolarda optimalliğe yakınlığı sağlama görevini üstlenmektedir. $\lambda$ değeri büyüdükçe çözümün veri setindeki değişkenliklere daha az duyarlı olmasını sağlamaktadır. Bir diğer robust model parametresi olan $\omega$ ise modelin sağlamlığ ile ilgili olarak, robust model çözümünün bütün senaryolarda neredeyse olurlu olmasını sağlayacak şekilde, doyurulması zorunlu kısıtlardan sapmaları cezalandıran bir katsayıdır. Farklı $\lambda$ değerleri için sonuçlar değerlendirildikten ve uygun ceza katsayıları belirlendikten sonra, en uygun $\lambda$ değerinin 
seçimine yönelik olarak robust amaç değerleri, beklenen maliyetleri, beklenen sapmalar, çözüm sağlamlığ1 ve model sağlamlığ 1 değerleri için karşılaştırma testleri yapılmıştır.

Yapılan karşılaştırmalı analizler değerlendirildiğinde $\lambda=0.1$ değerinin gerek maliyet, gerek sağlamlık açısından daha uygun sonuçlar verdiği görülmüş̧ür. Tablo 6 ' da $\lambda=0.1$ için robust model sonuçları verilmiştir.

Tablo 6: $\lambda=0.1$ için Robust Model Çözüm Sonuçları

\begin{tabular}{|c|c|c|c|c|c|}
\hline$\omega$ & $\begin{array}{l}\text { Robust } \\
\text { Amaç }\end{array}$ & $\begin{array}{c}\text { Beklenen } \\
\text { Maliyet }\end{array}$ & $\begin{array}{c}\text { Beklenen } \\
\text { Sapma }\end{array}$ & $\begin{array}{c}\text { Çözüm } \\
\text { Sağlamlığı }\end{array}$ & $\begin{array}{c}\text { Model } \\
\text { Sağlamlığı }\end{array}$ \\
\hline 0 & $26,311,076.60$ & $26,036,480.00$ & $2,745,965.99$ & $26,311,076.60$ & $190,800.00$ \\
\hline 1 & $26,698,603.14$ & $26,037,390.00$ & $4,679,131.36$ & $26,505,303.14$ & $193,300.00$ \\
\hline 10 & $29,075,631.79$ & $26,053,320.00$ & $16,478,117.88$ & $27,701,131.79$ & $137,450.00$ \\
\hline 20 & $31,501,865.25$ & $29,238,510.00$ & $12,854,028.73$ & $30,523,912.87$ & $48,897.62$ \\
\hline 30 & $32,774,779.62$ & $29,450,660.00$ & $18,171,196.20$ & $31,267,779.62$ & $50,233.33$ \\
\hline 40 & $34,988,886.52$ & $28,312,500.00$ & $34,864,341.37$ & $31,798,934.14$ & $79,748.81$ \\
\hline 50 & $33,517,878.07$ & $30,879,040.00$ & $14,814,571.15$ & $32,360,497.12$ & $23,147.62$ \\
\hline 60 & $34,496,311.96$ & $31,365,460.00$ & $17,305,662.44$ & $33,096,026.24$ & $23,338.10$ \\
\hline 70 & $34,957,344.43$ & $31,601,090.00$ & $18,450,877.61$ & $33,446,177.76$ & $21,588.10$ \\
\hline 80 & $35,630,036.18$ & $31,501,010.00$ & $22,301,690.37$ & $33,731,179.04$ & $23,735.71$ \\
\hline 90 & $34,384,540.50$ & $32,175,220.00$ & $12,739,633.56$ & $33,449,183.36$ & $10,392.86$ \\
\hline 100 & $33,073,793.27$ & $31,729,050.00$ & $8,387,908.89$ & $32,567,840.89$ & $5,059.52$ \\
\hline 110 & $33,322,602.80$ & $31,657,210.00$ & $9,988,451.82$ & $32,656,055.18$ & $6,059.52$ \\
\hline 120 & $33,443,793.28$ & $31,657,210.00$ & $10,594,404.20$ & $32,716,650.42$ & $6,059.52$ \\
\hline 200 & $34,325,829.01$ & $31,853,630.00$ & $14,036,275.78$ & $33,257,257.58$ & $5,342.86$ \\
\hline 300 & $36,727,244.59$ & $31,813,350.00$ & $26,240,731.57$ & $34,437,423.16$ & $7,632.74$ \\
\hline 400 & $36,778,092.85$ & $31,969,250.00$ & $25,726,523.70$ & $34,541,902.37$ & $5,590.48$ \\
\hline 500 & $34,719,705.77$ & $31,670,900.00$ & $16,910,676.76$ & $33,361,967.68$ & $2,715.48$ \\
\hline 600 & $36,697,059.61$ & $32,510,000.00$ & $22,652,738.94$ & $34,775,273.89$ & $3,202.98$ \\
\hline 700 & $37,214,635.47$ & $31,923,630.00$ & $28,139,221.39$ & $34,737,552.14$ & $3,538.69$ \\
\hline 800 & $39,139,038.88$ & $31,759,590.00$ & $38,570,679.29$ & $35,616,657.93$ & $4,402.98$ \\
\hline 900 & $38,626,947.63$ & $32,090,700.00$ & $34,376,761.99$ & $35,528,376.20$ & $3,442.86$ \\
\hline 950 & $37,205,994.02$ & $31,661,330.00$ & $29,389,497.33$ & $34,600,279.73$ & $2,742.86$ \\
\hline 960 & $38,145,947.92$ & $31,677,710.00$ & $34,008,093.53$ & $35,078,519.35$ & $3,195.24$ \\
\hline 970 & $40,243,331.15$ & $31,697,100.00$ & $44,398,978.12$ & $36,136,997.81$ & $4,233.33$ \\
\hline 974 & $39,924,022.91$ & $31,837,000.00$ & $42,107,348.11$ & $36,047,734.81$ & $3,979.76$ \\
\hline 975 & $37,304,820.92$ & $31,676,310.00$ & $29,809,216.33$ & $34,657,231.63$ & $2,715.48$ \\
\hline 980 & $37,331,975.68$ & $31,676,310.00$ & $29,944,990.14$ & $34,670,809.01$ & $2,715.48$ \\
\hline 1,000 & $37,440,594.73$ & $31,676,310.00$ & $30,488,085.38$ & $34,725,118.54$ & $2,715.48$ \\
\hline 1,100 & $37,978,277.20$ & $31,670,900.00$ & $33,203,533.90$ & $34,991,253.39$ & $2,715.48$ \\
\hline 1,200 & $38,521,372.44$ & $31,670,900.00$ & $35,919,010.09$ & $35,262,801.01$ & $2,715.48$ \\
\hline 1,300 & $39,064,467.68$ & $31,670,900.00$ & $38,634,486.28$ & $35,534,348.63$ & $2,715.48$ \\
\hline 1,400 & $39,607,562.91$ & $31,670,900.00$ & $41,349,962.47$ & $35,805,896.25$ & $2,715.48$ \\
\hline 1,500 & $40,150,658.15$ & $31,670,900.00$ & $44,065,438.66$ & $36,077,443.87$ & $2,715.48$ \\
\hline
\end{tabular}

Firma katlanabileceği maliyet ölçüsünde bir ceza katsayısı seçerek sonuçlarını uygulama yoluna gidebilecektir. $\lambda=0.1$ olduğunda amaç fonksiyonunun değeri, beklenen maliyet, beklenen sapma, model sağlamlığı ve çözüm sağlamlığı açısından en uygun sonuçlar zorunlu kısıttan sapmanın 100 birim ile cezalandırıldığı durumda elde edilmiştir. Zorunlu kısıttan sapma 100 birim ile cezalandırılırsa $(\omega=100)$, kısıttan sapma 5,059.52 metre, beklenen amaç değerinden sapmalar toplamı 8,387,908.89 TL ve robust amaç değeri 33,073,793.27 TL olarak gerçekleşir. Firma model sağlamlığını arttırmak isterse model sağlamlığı değerinde en dikkat çekici kırılmanın yaşandığı 50'yi veya kısıttan sapmanın en az düzeyde olduğu 975'i ceza katsayısı olarak belirleyebilir, ancak bu durumda daha fazla maliyete katlanmas1 gerekecektir. Diğer yandan firma, kısıtın doyurulmasından çok maliyetin enküçüklenmesini önemsiyorsa çözüm sağlamlığı değerine göre karar verebilir, ancak bu noktada dikkat edilmesi gereken çözüm 
sağlamlığı arttıkça model sağlamlığının azalmasıdır. Çözüm sağlamlığının en iyi olduğu (çözüm sağlamlığı değerinin en küçük olduğu) nokta kısıttan sapmaların en büyük olduğu noktadır. En ideal karar her iki sağlamlık kriterinin birlikte göz önüne alınarak verilen karar olacaktır. Model sağlamlığı ve çözüm sağlamlığı birlikte değerlendirildiğinde $\lambda=0.1$ olduğunda firma için ceza katsayısının 100 olarak seçilmesinin uygun olduğu görülmektedir.

Çözüm sağlamlığı ile model sağlamlığı robust amaç fonksiyonunda birbirinin tersi yönlü olarak çalışmaktadır. Çözüm sağlamlığının değeri yükseldikçe, başka bir deyişle, optimal amaç fonksiyonu değerinden sapma büyüdükçe, model sağlamlığı değeri düşmektedir. Bu durum Grafik 1'de ortaya konmuştur. Grafikte yatay eksen $\omega$ değerlerini gösterirken, dikey eksenlerden biri çözüm sağlamlığı değerlerini diğeri model sağlamlığı değerlerini göstermektedir. Grafikte de görüldüğü gibi, çözüm sağlamlığı değeri artarak, model sağlamlığı değer, de azalarak belirli bir değerden sonra sabitlenmektedir.

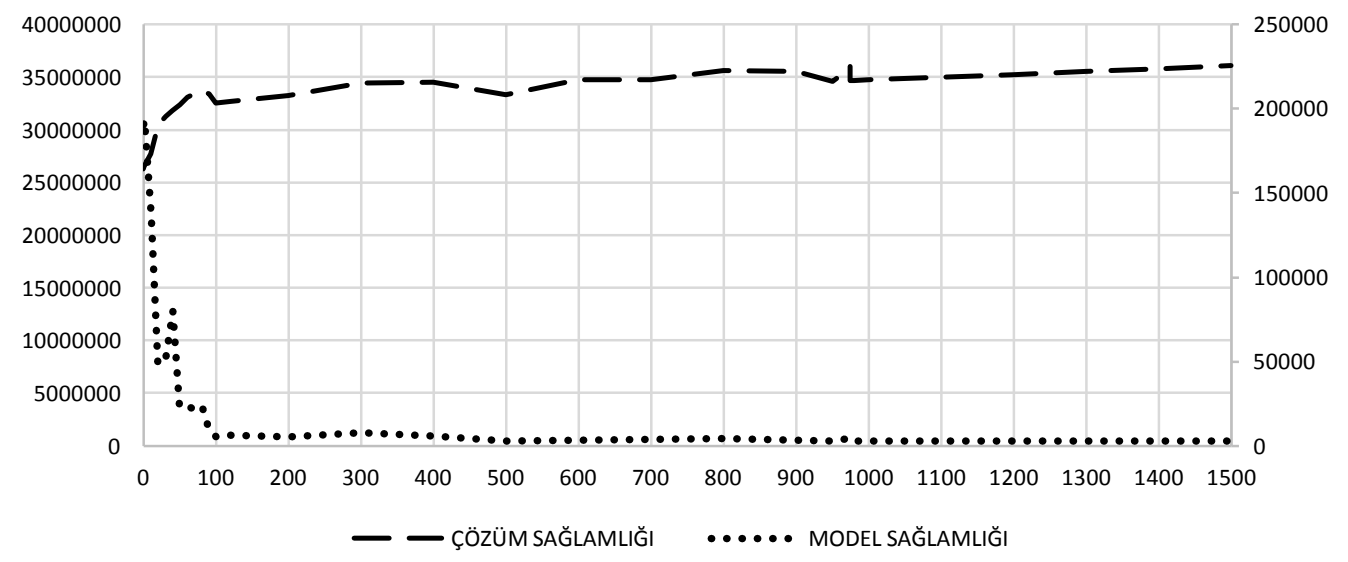

Grafik 1: $\lambda=0.1$ için Çözüm Sağlamlığı ile Model Sağlamlığı Arasındaki Değişim

Senaryoların ayrı ayrı ve olasılıkları $p_{1}^{S}=0.25, p_{2}^{S}=0.40$ ve $p_{3}^{S}=0.35$ olacak şekilde beklenen değerleri alınarak oluşturulan ortalama değer senaryosu ile robust yaklaşımın sonuçları Tablo 7 , Tablo 8, Tablo 9, Tablo 10, Tablo 11 ve Tablo 12'de verilmiştir.

\section{Tablo 7: Modellerin Amaç Fonksiyonu Sonuçları}

\begin{tabular}{|c|c|}
\hline & MALIYET \\
\hline Senaryo 1 & $27,218,370.88$ \\
\hline Senaryo 2 & $31,122,469.31$ \\
\hline Senaryo 3 & $34,230,372.63$ \\
\hline Ortalama Değer Yaklaşımı (ODY) & $31,393,139.88$ \\
\hline Robust Yaklaşım (RY) & $33,073,793.27$ \\
\hline Beklenen Maliyet & $31,729,050.00$ \\
\hline
\end{tabular}

Tablo 7'de amaç fonksiyonu değerleri verilmiştir. Toplam maliyet deterministik birinci senaryo için 27,218,370.88, ikinci senaryo için 31,122,469.31, üçüncü senaryo için 34,230,372.63 olarak gerçekleşmiştir. Belirsiz parametrelerin beklenen değeri alınarak oluşturulan ortalama değer senaryosunun maliyeti 31,393,139.88 iken, bu senaryolar için robust model maliyeti $33,073,793.27$, robust modelin sapmasız ve cezasız beklenen maliyeti ise 31,729,050.00 olarak hesaplanmıştır. Literatürde çok benzer bir çalışma Rahmanı vd. tarafindan 2013 yılında yapılmış, farklı senaryo setleri ve senaryo olasılıklarının tümünde robust modelin beklenen değer yaklaşımından daha düşük maliyetlerle sonuçlandığı gösterilmiştir. Ancak bu sonuçların hangi $\lambda$ ve $\omega$ değeri için ortaya çıktığı belirtilmemiştir. Sapma ve ceza maliyetlerinden dolayı modelin toplam maliyetinin senaryoların toplam maliyetinden yüksek çıkması olası ve beklenen bir durumdur. Belirlenen $\lambda$ ve $\omega$ parametrelerinin değerleri sonucu 
büyük ölçüde etkilemektedir. Bu çalışmasın yapılan çözümlemede $\lambda=0.1$ için $\omega$ 'nın 20 ve daha küçük olduğu robust modellerin toplam maliyetinin ortalama değer yaklaşımının maliyetinden daha düşük olduğu görülmüştür (Tablo 6).

Tablo 8: Modellere Göre Hammadde Satınalma Miktarları

\begin{tabular}{lcccccc}
\hline & $\mathbf{W}_{\mathbf{1 1}}$ & $\mathbf{W}_{\mathbf{1 2}}$ & $\mathbf{W}_{\mathbf{1 3}}$ & $\mathbf{W}_{\mathbf{1 4}}$ & $\mathbf{W}_{\mathbf{1 5}}$ & $\mathbf{W}_{\mathbf{1 6}}$ \\
\hline RY & $1,127,872.43$ & 0 & 0 & $844,950.00$ & 0 & 0 \\
ODY & $1,123,671.25$ & 0 & 0 & $774,000.00$ & 0 & 0 \\
S1 & $1,122,650.00$ & 0 & 0 & $351,525.00$ & $516,000.00$ & 0 \\
S2 & $1,086,151.19$ & 0 & 0 & $754,650.00$ & 0 & 0 \\
S3 & $1,107,600.00$ & 0 & 0 & $774,000.00$ & 0 & 0 \\
\hline & $\mathbf{W}_{\mathbf{2 1}}$ & $\mathbf{W}_{\mathbf{2 2}}$ & $\mathbf{W}_{\mathbf{2 3}}$ & $\mathbf{W}_{\mathbf{2 4}}$ & $\mathbf{W}_{\mathbf{2 5}}$ & $\mathbf{W}_{\mathbf{2 6}}$ \\
\hline RY & $271,714.29$ & $246,714.29$ & $246,714.29$ & $229,500.00$ & $180,000.00$ & $180,000.00$ \\
ODY & $274,714.29$ & $246,714.29$ & $243,783.93$ & $180,000.00$ & $180,000.00$ & $180,000.00$ \\
S1 & $274,714.29$ & $246,714.29$ & $243,071.43$ & $245,250.00$ & $180,000.00$ & $180,000.00$ \\
S2 & $274,714.29$ & $246,714.29$ & $217,607.43$ & $187,500.00$ & $169,500.00$ & $169,500.00$ \\
S3 & $274,714.29$ & $246,714.29$ & $232,571.43$ & $180,000.00$ & $180,000.00$ & $180,000.00$ \\
\hline & $\mathbf{W}_{\mathbf{3 1}}$ & $\mathbf{W}_{\mathbf{3 2}}$ & $\mathbf{W}_{\mathbf{3 3}}$ & $\mathbf{W}_{\mathbf{3 4}}$ & $\mathbf{W}_{\mathbf{3 5}}$ & $\mathbf{W}_{\mathbf{3 6}}$ \\
\hline RY & $5,334,285.71$ & 0 & 0 & $3,930,000.00$ & 0 & 0 \\
ODY & $5,314,750.00$ & 0 & 0 & $3,600,000.00$ & 0 & 0 \\
S1 & $5,310,000.00$ & 0 & 0 & $4,035,000.00$ & 0 & 0 \\
S2 & $5,140,238.10$ & 0 & 0 & $3,510,000.00$ & 0 & 0 \\
S3 & $5,240,000.00$ & 0 & 0 & $3,600,000.00$ & 0 & 0 \\
\hline
\end{tabular}

Üretim planların sonucu ortaya çıkan dönemlere göre hammadde satınalma miktarları Tablo 8'de gösterilmiştir. Firmanın birinci ve üçüncü hammaddeden genel olarak birinci ve altıncı dönemlerde alım yapması gerekirken, ikinci hammaddeden her dönem sipariş vermesi gerekmektedir. Senaryo 1'in gerçekleştiği durumda birinci hammaddeden beşinci dönemde de alım yapılması gerektiği görülmektedir. Miktarlar incelendiğinde robust model sonuçlarının, ortalama değer senaryosu ve birinci senaryonun büyük ölçüde benzerlik gösterdiği görülmektedir.

Tablo 9: Modellere Göre Hammadde Stoklama Miktarları

\begin{tabular}{lcccrcc}
\hline & $\mathbf{I R}_{\mathbf{1 1}}$ & $\mathbf{I R}_{\mathbf{1 2}}$ & $\mathbf{I R}_{\mathbf{1 3}}$ & \multicolumn{1}{c}{$\mathbf{I R}_{\mathbf{1 4}}$} & $\mathbf{I R}_{\mathbf{1 5}}$ & $\mathbf{I R}_{\mathbf{1 6}}$ \\
\hline RY & $774,247.62$ & $420,623.81$ & $67,000.00$ & $583,000.00$ & $325,000.00$ & $67,000.00$ \\
ODY & $770,047.44$ & $416,423.63$ & $67,000.00$ & $583,000.00$ & $325,000.00$ & $67,000.00$ \\
S1 & $769,026.19$ & $415,402.38$ & $67,000.00$ & $67,000.00$ & $325,000.00$ & $67,000.00$ \\
S2 & $732,527.38$ & $378,903.57$ & $67,000.00$ & $552,900.00$ & $309,950.00$ & $67,000.00$ \\
S3 & $753,976.19$ & $400,352.38$ & $67,000.00$ & $583,000.00$ & $325,000.00$ & $67,000.00$ \\
\hline & $\mathbf{I R}_{\mathbf{2 1}}$ & $\mathbf{I R}_{\mathbf{2 2}}$ & $\mathbf{I R}_{\mathbf{2 3}}$ & $\mathbf{I R}_{\mathbf{2 4}}$ & $\mathbf{I R}_{\mathbf{2 5}}$ & $\mathbf{I R}_{\mathbf{2 6}}$ \\
\hline RY & $25,000.00$ & $25,000.00$ & $25,000.00$ & $25,000.00$ & $25,000.00$ & $25,000.00$ \\
ODY & $25,000.00$ & $25,000.00$ & $25,000.00$ & $25,000.00$ & $25,000.00$ & $25,000.00$ \\
S1 & $25,000.00$ & $25,000.00$ & $25,000.00$ & $25,000.00$ & $25,000.00$ & $25,000.00$ \\
S2 & $25,000.00$ & $25,000.00$ & $25,000.00$ & $25,000.00$ & $25,000.00$ & $25,000.00$ \\
S3 & $25,000.00$ & $25,000.00$ & $25,000.00$ & $25,000.00$ & $25,000.00$ & $25,000.00$ \\
\hline & $\mathbf{I R}_{\mathbf{3 1}}$ & $\mathbf{I R}_{\mathbf{3 2}}$ & $\mathbf{I R}_{\mathbf{3 3}}$ & \multicolumn{1}{c}{$\mathbf{I R}_{\mathbf{3 4}}$} & $\mathbf{I R}_{\mathbf{3 5}}$ & $\mathbf{I R}_{\mathbf{3 6}}$ \\
\hline RY & $3,689,523.81$ & $2,044,761.91$ & $400,000.00$ & $280,000.00$ & $160,000.00$ & $400,000.00$ \\
ODY & $3,669,988.10$ & $2,025,226.19$ & $400,000.00$ & $280,000.00$ & $160,000.00$ & $400,000.00$ \\
S1 & $3,665,238.00$ & $2,020,476.19$ & $400,000.00$ & $280,000.00$ & $160,000.00$ & $400,000.00$ \\
S2 & $3,495,476.19$ & $1,850,714.29$ & $400,000.00$ & $280,000.00$ & $160,000.00$ & $400,000.00$ \\
S3 & $3,595,238.10$ & $1,950,476.19$ & $400,000.00$ & $280,000.00$ & $160,000.00$ & $400,000.00$ \\
\hline
\end{tabular}

Tablo 9'dan hammadde stoklama miktarları incelendiğinde ikinci hammadde için stoklama miktarının tüm senaryolar ve robust yaklaşım için aynı ve firmanın belirlediği en büyük stok kapasitesine eşit olduğu görülmektedir. Firma, üretimde kullandığı ikinci hammadde 
için stok kapasitesini gözden geçirmelidir. Diğer değerler için özellikle ortalama değer ve robust yaklaşım sonuçlarının büyük ölçüde paralellik gösterdiği söylenebilir.

Birinci üretim aşamasının çıktısı olan yarımamül üretim miktarları Tablo 10 ile özetlenmiştir. Firmada yarımamül stoklanmadan ikinci aşamada işleme alındığı ve nihai ürünün üretilmesinde birebir oranda kullanıldığı için tabloda görülen miktarlar aynı zamanda dönemlerin toplam üretim miktarlarına eşit olmaktadır. Bu üretim miktarları ile birinci aşama için kapasite kullanım oranları ilk üç dönemde \%100, dördüncü dönemde \%93, diğer dönemlerde ise $\% 73$ olarak gerçekleşecektir.

Tablo 10: Modellere Göre Yarı Mamul Üretim Miktarı Sonuçları

\begin{tabular}{lcccccc}
\hline & $\mathbf{X}_{\mathbf{1 1}}$ & $\mathbf{X}_{\mathbf{1 2}}$ & $\mathbf{X}_{\mathbf{1 3}}$ & $\mathbf{X}_{\mathbf{1 4}}$ & $\mathbf{X}_{\mathbf{1 5}}$ & $\mathbf{X}_{\mathbf{1 6}}$ \\
\hline RY & $164,476.19$ & $164,476.19$ & $164,476.19$ & $153,000.00$ & $120,000.00$ & $120,000.00$ \\
ODY & $164,476.19$ & $164,476.19$ & $162,522.62$ & $120,000.00$ & $120,000.00$ & $120,000.00$ \\
S1 & $164,476.19$ & $164,476.19$ & $162,047.62$ & $163,500.00$ & $120,000.00$ & $120,000.00$ \\
S2 & $164,476.19$ & $164,476.19$ & $145,071.43$ & $125,000.00$ & $120,000.00$ & $120,000.00$ \\
S3 & $164,476.19$ & $164,476.19$ & $155,047.62$ & $120,000.00$ & $120,000.00$ & $120,000.00$ \\
\hline
\end{tabular}

Dönemlere göre nihai ürün üretim planları Tablo 11'de verilmiştir. Toplam üretim miktarları farklı senaryolar ve robust model arasında çok büyük farklılık göstermese de nihai ürünlerin dönemlere göre üretim miktarları değişmektedir. Dördüncü ürünün talebi yüksek ve izin verilen geç karşılanma oranı düşük olduğu için tüm dönemlerde mutlaka üretilmesi gerektiği görülmektedir. Birinci dönemde tüm ürün çeşitlerinden üretim yapılırken, diğer dönemlerde üretim farklı kombinasyonlarda gerçekleşecektir. Robust model sonucunda, ikinci ürünün beşinci ve altıncı dönemlerde üretimi yapılmazken, üçüncü ürünün sadece birinci dönemde üretilerek talebinin büyük ölçüde karşılanabilecektir.

Tablo 11: Modellere Göre Nihai Ürün Üretim Miktarı Sonuçları

\begin{tabular}{lcccccc}
\hline & $\mathbf{X X}_{\mathbf{1 1}}$ & $\mathbf{X X}_{\mathbf{1 2}}$ & $\mathbf{X X}_{\mathbf{1 3}}$ & $\mathbf{X X}_{\mathbf{1 4}}$ & $\mathbf{X X}_{\mathbf{1 5}}$ & $\mathbf{X X}_{\mathbf{1 6}}$ \\
\hline RY & $21,226.19$ & $27,250.00$ & $24,523.81$ & $20,000.00$ & $15,000.00$ & $22,000.00$ \\
ODY & $17,925.00$ & $46,300.00$ & 0 & $17,500.00$ & $31,500.00$ & $37,000.00$ \\
S1 & $23,226.19$ & $58,273.81$ & 0 & 0 & $10,000.00$ & $17,500.00$ \\
S2 & $18,750.00$ & $24,250.00$ & $22,500.00$ & $22,523.81$ & $19,976.19$ & $41,023.81$ \\
S3 & $53,750.00$ & 0 & 0 & $18,250.00$ & $63,000.00$ & 0 \\
\hline & $\mathbf{X X}_{\mathbf{2 1}}$ & $\mathbf{X X}_{\mathbf{2 2}}$ & $\mathbf{X X}_{\mathbf{2 3}}$ & $\mathbf{X X}_{\mathbf{2 4}}$ & $\mathbf{X X}_{\mathbf{2 5}}$ & $\mathbf{X X}_{\mathbf{2 6}}$ \\
\hline RY & $6,000.00$ & $25,952.38$ & 0 & $23,000.00$ & 0 & 0 \\
ODY & $7,201.19$ & $23,976.19$ & $42,522.62$ & 0 & 0 & 0 \\
S1 & $9,000.00$ & $27,000.00$ & 0 & $43,500.00$ & 0 & 0 \\
S2 & $6,000.00$ & $24,476.19$ & $8,047.62$ & $12,000.00$ & 0 & 0 \\
S3 & $7,226.19$ & $31,726.19$ & $35,047.62$ & 0 & 0 & 0 \\
\hline & $\mathbf{X X}_{\mathbf{3 1}}$ & $\mathbf{X X}_{\mathbf{3 2}}$ & $\mathbf{X X}_{\mathbf{3 3}}$ & $\mathbf{X X}_{\mathbf{3 4}}$ & $\mathbf{X X}_{\mathbf{3 5}}$ & $\mathbf{X X}_{\mathbf{3 6}}$ \\
\hline RY & $38,476.19$ & 0 & 0 & 0 & 0 & 0 \\
ODY & $2,850.00$ & $20,500.00$ & 0 & 0 & $9,750.00$ & 0 \\
S1 & $2,250.00$ & $4,500.00$ & $26,750,00$ & 0 & 0 & 0 \\
S2 & $45,476.19$ & 0 & 0 & 0 & 0 & 0 \\
S3 & $2,250.00$ & $12,750.00$ & 0 & 0 & 0 & 0 \\
\hline & $\mathbf{X X}_{\mathbf{4 1}}$ & $\mathbf{X X}_{\mathbf{4 2}}$ & $\mathbf{X X}_{\mathbf{4 3}}$ & $\mathbf{X X}_{\mathbf{4 4}}$ & $\mathbf{X X}_{\mathbf{4 5}}$ & $\mathbf{X X}_{\mathbf{4 6}}$ \\
\hline RY & $98,773.81$ & $111,273,81$ & $139,952.81$ & $110,000.00$ & $105,000.00$ & $98,000.00$ \\
ODY & $136,500.00$ & $73,700,00$ & $122,700.00$ & $102,500.00$ & $88,500.00$ & $83,000.00$ \\
S1 & $130,000.00$ & $73,700,00$ & $120,000.00$ & $102,500.00$ & $88,500.00$ & $83,000.00$ \\
S2 & $94,250.00$ & $115,750,00$ & $114,523.81$ & $90,476.19$ & $93,023.81$ & $71,976.19$ \\
S3 & $101,250.00$ & $108,952,38$ & $121,047.62$ & $90,000.00$ & $60,000.00$ & $77,500.00$ \\
\hline
\end{tabular}

Robust modelin verdiği üretim planına göre ikinci aşamanın üretim kapasitesinin ilk üç dönemde $\% 62$ 'si, dördüncü dönemde $\% 58$ 'i diğer tüm dönemlerde $\% 45$ 'i kullanılmış olacaktır. Firma, birinci, ikinci ve üçüncü dönemde ilk aşamada tam kapasite çalışacağı için bu 
dönemlerde daha fazla üretim gerçekleştiremez ancak diğer dönemlerde kapasiteyi daha yüksek oranda kullanmak adına stoka üretimi arttırabilir. Bu durumda artan maliyetlere katlanmak zorunda kalacaktır.

Firmanın güvenlik stoku politikası ürün bazlı olmadığ1 için oluşan planlara göre bazı ürünlerden bazı dönemlerde stok bulundurmaması gerektiği görülmektedir (Tablo 12). Önceki sonuç tablolarından farklı olarak nihai ürün stoklama tablosunda robust yaklaşıma ilişkin üç farklı sonuç verilmektedir. Bunun nedeni robust modelin tek bir üretim planı vermesine rağmen firmanın gelecekte karşılaşabileceği birden fazla senaryonun olmasıdır. Örneğin RY S1 satırı firmanın robust model sonucuna göre üretim yapması durumunda birinci senaryo gerçekleşirse nihai ürün stoklama miktarlarının dönemlerde nasıl olacağını göstermektedir. Ortaya çıkan üretim planları doğrultusunda birinci ve dördüncü ürünlerin üretim miktarları fazla olmasına rağmen talep miktarları yüksek olduğu için stoklandığ 1 dönem sayısı diğer iki ürüne göre daha azdir.

Tablo 12: Modellere Göre Nihai Ürün Stoklama Miktarları

\begin{tabular}{|c|c|c|c|c|c|c|}
\hline & $\mathrm{I}_{11}$ & $\mathrm{I}_{12}$ & $\mathrm{I}_{13}$ & $\mathrm{I}_{14}$ & $I_{15}$ & $\mathrm{I}_{16}$ \\
\hline RY S1 & 0 & 0 & 523.81 & $10,523.81$ & $15,523.81$ & $22,523.81$ \\
\hline RY S2 & 0 & $5,476.19$ & 0 & 0 & 0 & 0 \\
\hline RY S3 & $6,226.19$ & $13,476.19$ & $13,000.00$ & $17,000.00$ & $23,500.00$ & $35,500.00$ \\
\hline ODY & 0 & $20,775.00$ & 0 & $16,000.00$ & $36,450.00$ & 0 \\
\hline S1 & 0 & $31,500.00$ & $7,500.00$ & 0 & 0 & 0 \\
\hline S2 & 0 & 0 & 0 & 0 & 0 & $19,023.19$ \\
\hline \multirow[t]{2}{*}{ S3 } & $38,750.00$ & $18,750.00$ & 0 & 0 & $50,500.00$ & $40,500.00$ \\
\hline & $I_{21}$ & $I_{22}$ & $I_{23}$ & $I_{24}$ & $I_{25}$ & $I_{26}$ \\
\hline RY S1 & 0 & $14,500.00$ & 0 & $15,000.00$ & $11,000.00$ & 0 \\
\hline RY S2 & 0 & $11,952.38$ & $2,952.38$ & $16,952.38$ & $11,952.38$ & $1,952.00$ \\
\hline RY S3 & 0 & $19,952.38$ & $4,952.38$ & $17,952.38$ & $14,452.38$ & $9,652.38$ \\
\hline ODY & 0 & $12,152.38$ & $42,250.00$ & $33,350.00$ & $29,075.00$ & $20,025.00$ \\
\hline S1 & 0 & $14,500.00$ & 0 & $35,500.00$ & $31,500.00$ & $20,500.00$ \\
\hline S2 & 0 & $10,476.19$ & $9,523.81$ & $12,523.81$ & $7,523.81$ & 0 \\
\hline \multirow[t]{2}{*}{ S3 } & 0 & $24,952.38$ & $45,000.00$ & $35,000.00$ & $31,500.00$ & $26,700.00$ \\
\hline & $\mathbf{I}_{31}$ & $I_{32}$ & $I_{33}$ & $I_{34}$ & $I_{35}$ & $I_{36}$ \\
\hline RY S1 & $35,476.19$ & $30,476.19$ & $22,476.19$ & $18,476.00$ & $13,476.19$ & $10,476.19$ \\
\hline RY S2 & $40,000.00$ & $34,000.00$ & $30,000.00$ & $27,000.00$ & $24,500.00$ & $20,500.00$ \\
\hline RY S3 & $35,476.19$ & $32,476.19$ & $30,476.19$ & $28,476.19$ & $25,976.19$ & $23,476.19$ \\
\hline ODY & 0 & $14,650.00$ & $9,750.00$ & $6,650.00$ & $3,275.00$ & 0 \\
\hline S1 & 0 & 0 & $17,500.00$ & $13,500.00$ & $8,500.00$ & $5,500.00$ \\
\hline S2 & $40,476.19$ & $34,476.19$ & $30,476.19$ & $27,476.19$ & $24,976.19$ & $20,976.19$ \\
\hline \multirow[t]{2}{*}{ S3 } & 0 & $9,000.00$ & $7,000.00$ & $5,000.00$ & $2,500.00$ & 0 \\
\hline & $I_{41}$ & $\mathbf{I}_{\mathbf{4 2}}$ & $\mathbf{I}_{\mathbf{4 3}}$ & $I_{44}$ & $I_{45}$ & $I_{46}$ \\
\hline RY S1 & $8,773.81$ & 47.62 & $25,000.00$ & 0 & 0 & $8,000.00$ \\
\hline RY S2 & 0 & 47.62 & $25,000.00$ & $45,000.00$ & $75,000.00$ & $73,000.00$ \\
\hline RY S3 & 0 & $10,047.62$ & 0 & $10,000.00$ & $65,000.00$ & $103,000.00$ \\
\hline ODY & $40,000.00$ & $2,700.00$ & 0 & 0 & 0 & 0 \\
\hline S1 & $40,000.00$ & 0 & $15,000.00$ & 0 & 0 & $17,500.00$ \\
\hline S2 & 0 & 0 & 0 & 0 & $18,023.81$ & 0 \\
\hline S3 & $1,250.00$ & $21,250.00$ & 0 & 0 & 0 & $60,000,00$ \\
\hline
\end{tabular}

Son olarak Tablo 13'te modeller sonucu ortaya çıkan üretim planı izlendiği takdirde dönemlerde stok dışı kalınıp bir sonraki dönem karşılanacak olan talep miktarları verilmiştir. Sonuçlara göre robust modelin genel itibari ile firmayı daha düşük oranda geç teslim durumuna düşürecek bir üretim planı sunduğu söylenebilir. 
Tablo 13: Modellere Göre Geç Teslim (Backorder) Miktarı Sonuçları

\begin{tabular}{ccccccc}
\hline & $\mathbf{B}_{\mathbf{1 1}}$ & $\mathbf{B}_{\mathbf{1 2}}$ & $\mathbf{B}_{\mathbf{1 3}}$ & $\mathbf{B}_{\mathbf{1 4}}$ & $\mathbf{B}_{\mathbf{1 5}}$ & $\mathbf{B}_{\mathbf{1 6}}$ \\
\hline RY S1 & $6,250.00$ & 0 & 0 & 0 & 0 & 0 \\
RY S2 & $3,773.81$ & 0 & 0 & 0 & 0 & 0 \\
RY S3 & 0 & 0 & 0 & 0 & 0 & 0 \\
ODY & $5,975.00$ & 0 & $5,875.00$ & $3,875.00$ & 0 & 0 \\
S1 & $5,773.81$ & 0 & 0 & $2,500.00$ & $2,500.00$ & 0 \\
S2 & $6,250.00$ & 0 & $7,500.00$ & $4,976.19$ & 0 & 0 \\
S3 & 0 & 0 & $6,250.00$ & $4,000.00$ & 0 & 0 \\
\hline \multicolumn{1}{c}{$\mathbf{B}_{\mathbf{2 1}}$} & $\mathbf{B}_{\mathbf{2 2}}$ & $\mathbf{B}_{\mathbf{2 3}}$ & $\mathbf{B}_{\mathbf{2 4}}$ & $\mathbf{B}_{\mathbf{2 5}}$ & $\mathbf{B}_{\mathbf{2 6}}$ \\
\hline RY S1 & $1,952.38$ & 0 & 0 & 0 & 0 & 0 \\
RY S2 & $2,000.00$ & 0 & 0 & 0 & 0 & 0 \\
RY S3 & 0 & 0 & 0 & 0 & 0 & 0 \\
ODY & $2,198.81$ & 0 & 0 & 0 & 0 & 0 \\
S1 & $3,000.00$ & 0 & 0 & $1,595.24$ & $2,750.00$ & 0 \\
S2 & $2,000.00$ & 0 & 0 & 0 & 0 & $2,476.19$ \\
S3 & 773.81 & 0 & 0 & 0 & 0 & 0 \\
\hline & $\mathbf{B}_{\mathbf{3 1}}$ & $\mathbf{B}_{\mathbf{3 2}}$ & $\mathbf{B}_{\mathbf{3 3}}$ & $\mathbf{B}_{\mathbf{3 4}}$ & $\mathbf{B}_{\mathbf{3 5}}$ & $\mathbf{B}_{\mathbf{3 6}}$ \\
\hline RY S1 & 0 & 0 & 0 & 0 & 0 & 0 \\
RY S2 & 0 & 0 & 0 & 0 & 0 & 0 \\
RY S3 & 0 & 0 & 0 & 0 & 0 & 0 \\
ODY & 950.00 & 0 & 0 & 0 & 0 & 0 \\
S1 & 750.00 & $1,250.00$ & 0 & 0 & 0 & 0 \\
S2 & 0 & 0 & 0 & 0 & 0 & 0 \\
S3 & 750.00 & 0 & 0 & 0 & 0 & 0 \\
\hline & $\mathbf{B}_{\mathbf{4 1}}$ & $\mathbf{B}_{\mathbf{4 2}}$ & $\mathbf{B}_{\mathbf{4 3}}$ & $\mathbf{B}_{\mathbf{4 4}}$ & $\mathbf{B}_{\mathbf{4 5}}$ & $\mathbf{B}_{\mathbf{4 6}}$ \\
\hline RY S1 & 0 & 0 & 0 & $15,000.00$ & $10,000.00$ & 0 \\
RY S2 & $1,226.19$ & 0 & 0 & 0 & 0 & 0 \\
RY S3 & $1,226.19$ & 0 & 0 & 0 & 0 & 0 \\
ODY & 0 & 0 & 0 & $11,000.00$ & 0 & 0 \\
S1 & 0 & $5,297.62$ & 0 & $15,000.00$ & $5,000.00$ & 0 \\
S2 & $5,750.00$ & 0 & 476.19 & 0 & 0 & $10,000.00$ \\
S3 & 0 & 0 & $8,750.00$ & $7,000.00$ & 0 & 0 \\
\hline & & & & & & \\
\hline
\end{tabular}

\section{SONUÇ ve DEĞERLENDİRME}

Robust eniyileme, belirsiz girdi verilerinin ortaya çıkabilecek tüm değerleri için optimal ya da optimale yakın sonuçlar veren bir matematiksel yöntemdir. Yöntem, model parametrelerine ilişkin veri eksikliği durumunda, belirsiz verilerin herhangi bir olasıllk dağılımına uymadığı durumlarda, belirsizliklerin olasılıklı senaryolar ile ele alınabildiği durumlarda etkin bir şekilde kullanılabilmektedir.

Bu çalışmada esas amaç, belirsiz koşullar içeren kapasite kısıtlı çok ürünlü çok aşamalı üretim probleminin modellenerek robust eniyileme yöntemiyle çözümünü gerçekleştirmektir. Bu amaçla tekstil sektöründe faaliyet gösteren bir firmanın iki aşamalı, dört ürünlü, kapasite kısıtll, talep ve hammadde fiyatları belirsiz olan üretim sistemi için robust eniyileme modeli formüle edilip çözümü yapılmış, sağlam bir üretim planı oluşturularak yöntemin uygulanabilirliği gösterilmiştir.

Oluşturulan robust model, firma için iki çeşit sağlamlık ile ilgili bilgi sunmaktadır. $\mathrm{Bu}$ iki sağlamlık türünden ilki, çözüm sağlamlığı, belirlenen senaryoların optimal değerlerinden sapmalara izin vererek, tüm senaryolar için en iyi ya da en iyiye yakın sonuç verecek üretim planının belirlenmesini sağlamaktadır. İkincisi, model sağlamlığı ise doyurulması zorunlu kısıtları esneterek gerçekleşebilecek senaryoların tümünde ya da çoğunluğunda yüksek düzeyde 
olurluluğu yakalamayı amaçlamaktadır. Çözüm sağlamlığı ve model sağlamlığı birbine ters olarak çalışmaktadır. Diğer bir ifade ile kısıtlardan sapma küçüldükçe (olurluluk düzeyi yükseldikçe), planın maliyeti yükselmektedir. $\mathrm{Bu}$ durum çözüm sonuçları için grafikle gösterilerek desteklenmiştir.

Robust yöntem ile maliyet enküçüklemesi ve talebin belirli oranlarda karşılanma zorunluluğu hedefleri birlikte ele alınmıştır. Yöntem, robust model parametrelerinin $(\lambda$ ve $\omega)$ farklı değerleri için karar vericiye farklı alternatif planlar sunmaktadır. Alternatif planların maliyeti çözümün sağlamlığına ve modelin sağlamlığına göre farklılık göstermektedir. Yapılan analizler sonucunda çözüm varyansının katsayısı olarak $\lambda=0.1$, kısıttan sapmaları cezalandıran katsayı olarak $\omega=100$ değerleri seçilmiştir. Seçilen en uygun parametre değerleri doğrultusunda oluşan robust üretim planın maliyeti 33,073,793.27 TL, senaryoların beklenen değerlerinden sapmalar toplamı $838,708.89$ ve karşılanması zorunlu talep hedefinden sapmalar toplamı 5,059.52 metre olarak gerçekleşmiştir.

Robust plan sonuçları, deterministik üç senaryo ve bir ortalama değer senayosu sonucunda ortaya çıkan planlar ile dönemlere göre hammadde alım ve stoklama miktarları, yarımamül üretim miktarları, nihai ürün üretim ve stoklama miktarı, geç karşılanan talep miktarları bazında karşılaştırmalı olarak raporlanmıştır. Buna göre firmanın üretim planı, talebi yüksek olan birinci ve dördüncü ürünlerin her dönem üretilmesi, talebi düşük olan ikinci ve üçüncü ürünlerin üretiminin belirli dönemlerde stoka üretilirek diğer dönemlerde talebin stoklardan karşılanması yönünde olmuştur. Çözüm sonucu elde edilen üretim planı, gelecekte karşılaşılabilecek tüm senaryolar için olurlu ve optimale yakın sonuçlar üretirken bazı senaryolardan daha yüksek maliyet ürettiği görülmüştür. Modelin daha yüksek maliyette gerçekleşmesinin nedeni optimallikten ve olurluluktan uzaklığı cezalandırmasıdır ve yüksek maliyet beklenen bir sonuçtur. Parametrelere göre yapılan bu seçim bağlayıcı değildir. Firma, farklı sağlamlıkta, daha düşük ya da daha yüksek maliyetli başka katsayılar seçebilir, sonuçlarını uygulayabilir.

Dönemlerin toplam üretim miktarları bütün senaryolarda ve robust sonuçta birbirlerine yakın, hatta çoğu durumda eşit çıkmasına rağmen modellerin üretim planları birbirinden farklıdır. Analiz sonuçları işletmenin üretimde kullandığı ikinci hammadde için en az stok miktarının ihtiyacın üzerinde olarak belirlediği gerçeğini ortaya çıkarmıştır.

Robust eniyileme modelleri ile gelecekte ortaya çıkması muhtemel tüm senaryolar göz önüne alınarak tek bir üretim planı oluşturulur. Bu sayede işletmelerin karşılaşabilecekleri durumları bu günden değerlendirebilmesi sağlanarak proaktif kararlar sonucunda muhtemel kriz ortamlarının büyük ölçüde önüne geçilebilir. Bu modeller ile birden çok hedefi olan, büyük boyutlu, karmaşı modeller doğrusal bir yapıda basit bir şekilde çözülebilir. Robust eniyileme, işletmelere farklı karar alternatifleri sunarak planlara öznellik katarken, deterministik modeller sonucunda ortaya çıkan katı planlara esneklik kazandırmaktadır. Diğer yandan, daha sağlam sonuçlar elde etmek için senaryoların eksiksiz ve doğru bir şekilde oluşturulmasının ve olasılık değerlerinin belirlenmesinin zor olması, farklı yöntemlere göre daha yüksek maliyetli planlar sunması yönteme karşı olumsuz ön yargılar oluşturabilmesi robust eniyilemenin dezavantajlı yönleri olarak sayılabilir.

Bundan sonraki çalışmalarda, 1) Firmanın geçmişte gerçeleşen üretim verileri ile geçmiş talep ve parametre değerleri ile çözülen robust modelin sonuçları ve diğer senaryoların ürettiği sonuçlar karşılaştırılabilir. 2) Yu ve Li Modelinin sonuçları senaryo tabanlı ve küme tabanlı alternatif modellerin sonuçları ile karşılaştırılabilir. 3) Farklı üretim süreçleri için (çok aşamalı, çok makineli, üretim sırasının önemli olduğu, vs.) robust üretim planlama ve programlama modelleri oluşturularak modelin uygulanabilirliğine bakılabilir. 4) Hedef sayısı ikiden fazla olması durumunda robust modelin çözülebilirliği ve etkinliği değerlendirilebilir. 5) Aynı ve/vaya farklı sektörlerde uygulamalar yapılabilir. 6) Robust modellemenin bulanık ya da gri mantık ile 
birlikte ele alındığı hibrit yöntemler geliştirilebilir. 7)Amaç fonksiyonu kazanç, kar ya da fayda enbüyüklemesi olacak şekilde üretim planlaması alanında yeni robust modeller türetilebilir. 8) Uygun robust parametre değerlerinin belirlenmesine ve/veya seçimine yönelik analitik yöntemler geliştirilebilir.

\section{KAYNAKÇA}

Adasme, P., Lisser, A., ve Soto, I. (2011) "Robust Semidefinite Relaxations for a Quadratic OFDMA Resource Allocation Scheme”, Computers \& Operations Research, 38(10): 1377-1399.

Adida, E., ve Joshi, P. (2009) “A Robust Optimisation Approach to Project Scheduling and Resource Allocation”, International Journal of Services Operations and Informatics, 4(2): 169-193.

Adida, E., ve Perakis, G. (2006) “A Robust Optimization Approach to Dynamic Pricing and İnventory Control with no Backorders”, Mathematical Programming, 107(1-2): 97-129.

Adida, E., ve Perakis, G. (2010) "Dynamic Pricing and İnventory Control: Robust vs. Stochastic Uncertainty ModelsA Computational Study" Annals of Operations Research, 181(1): 125-157.

Aghezzaf, E. (2005) "Capacity Planning and Warehouse Location in Supply Chains with Uncertain Demands", Journal of the Operational Research Society, 56(4): 453-462.

Agra, A., Christiansen, M., Figueiredo, R., Hvattum, L. M., Poss, M. ve Requejo, C. (2013) “The Robust Vehicle Routing Problem with Time Windows”, Computers \& Operations Research, 40(3): 856-866.

Ait-Alla, A., Teucke, M., Lütjen, M., Beheshti-Kashi, S. ve Karimi, H.R. (2014) "Robust Production Planning in Fashion Apparel Industry under Demand Uncertainty via Conditional Value at Risk", Hindawi Publishing Corporation Mathematical Problems in Engineering, Cilt 2014.

Alem, D. J. ve Morabito, R. (2012) "Production Planning in Furniture Settings via Robust Optimization", Computers\&Operations Research, 30: 139-150.

Aloulou, M. A., Dolgui, A., \& Kovalyov, M. Y. (2014). A Bibliography of Non-Deterministic Lot-Sizing Models. International Journal of Production Research. 52(8): 2293-2310.

Atamtürk, A., ve Zhang, M. (2007) "Two-Stage Robust Network Flow and Design under Demand Uncertainty", Operations Research, 55(4): 662-673.

Ayuso, A. A., \& Sánchez, M. T. O. (2007). On Modelling Planning Under Uncertainty in Manufacturing. SORT: Statistics and Operations Research Transactions. 31(2): 109-150.

Babonneau, F., Vial, J. P., Klopfenstein, O., ve Ouorou, A. (2013) "Robust Capacity Assignment Solutions for Telecommunications Networks with Uncertain Demands”, Networks. 62(4): 255-272.

Baghalian, A., Rezapour, S., ve Farahani, R. Z. (2013) "Robust Supply Chain Network Design with Service Level Against Disruptions and Demand Uncertainties: A Real-Life Case", European Journal of Operational Research, 227(1): 199-215.

Barahona, F., Bermon, S., Günlük, O., ve Hood, S. (2005) "Robust Capacity Planning in Semiconductor Manufacturing", Naval Research Logistics (NRL),52(5): 459-468.

Bel-Tal, A., El Ghaoui, L. ve Nemirowski, A. (2009) Robust Optimization, USA: Princeton University Press.

Ben-Tal, A., ve Nemirovski, A. (1998) "Robust Convex Optimization”, Mathematics of Operations Research, 23(4): 769-805.

Ben-Tal, A., ve Nemirovski, A. (1999) "Robust Solutions of Uncertain Linear Programs", Operations Research Letters. 25(1): 1-13.

Ben-Tal, A., \& Nemirovski, A. (2000) "Robust Solutions of Linear Programming Problems Contaminated with Uncertain Data", Mathematical Programming, 88(3): 411-424.

Ben-Tal, A., ve Nemirovski, A. (2002) "Robust Optimization-Methodology and Applications", Mathematical Programming, 92(3): 453-480.

Berglund, P. G., ve Kwon, C. (2014) "Robust Facility Location Problem for Hazardous Waste Transportation", Networks and Spatial Economics, 14(1): 91-116.

Bertsimas, D., ve Sim, M. (2003) "Robust Discrete Optimization and Network Flows", Mathematical Programming, 98(1-3): 49-71. 
Bertsimas, D., ve Thiele, A. (2004) “A Robust Optimization Approach to Supply Chain Management”, Integer Programming and Combinatorial Optimization (ss. 86-100), Springer Berlin Heidelberg.

Bertsimas, D., ve Thiele, A. (2006) “A Robust Optimization Approach to Inventory Theory”, Operations Research, 54(1): 150-168.

Bertsimas, D., Brown, D. B., \& Caramanis, C. (2011) "Theory and Applications of Robust Optimization", SIAM Review, 53(3): 464-501.

Büsing, C. (2012) "Recoverable Robust Shortest Path Problems”, Networks, 59(1): 181-189.

Chen, W., Tan, S., ve Yang, D. (2011) "Worst-Case VaR and Robust Portfolio Optimization with Interval Random Uncertainty Set", Expert Systems with Applications, 38(1): 64-70: 99.

Conde, E. (2009) “A Minmax Regret Approach to the Critical Path Method with Task Interval Times", European Journal of Operational Research, 197(1): 235-242.

De Rosa, V., Gebhard, M., Hartmann, E., ve Wollenweber, J. (2013) "Robust Sustainable Bi-Directional Logistics Network Design under Uncertainty”, International Journal of Production Economics, 145(1): 184-198.

Dolgui, A., Grimaud, F., \& Shchamialiova, K. (2010). Supply Chain Management Under Uncertainties: Lot-sizing and Scheduling Rules. In Artificial Intelligence Techniques for Networked Manufacturing Enterprises Management (ss. 181-220). London: Springer.

Fliege, J., ve Werner, R. (2014) "Robust Multiobjective Optimization \& Applications in Portfolio Optimization", European Journal of Operational Research, 234(2): 422-433.

Ghaoui, L. E., Oks, M., ve Oustry, F. (2003) "Worst-Case Value-at-Risk and Robust Portfolio Optimization: A Conic Programming Approach", Operations Research, 51(4): 543-556.

Goldfarb, D., ve Iyengar, G. (2003) "Robust Portfolio Selection Problems", Mathematics of Operations Research, 28(1): 1-38.

Gounaris, C. E., Wiesemann, W., ve Floudas, C. A. (2013) "The Robust Capacitated Vehicle Routing Problem Under Demand Uncertainty”, Operations Research, 61(3): 677-693.

Graves, S. C. (2011). Uncertainty and Production Planning. In Planning Production and Inventories in the Extended Enterprise (ss. 83-101). Springer US.

Gülpınar, N., Pachamanova, D., ve Çanakoğlu, E. (2013) "Robust Strategies for Facility Location under Uncertainty", European Journal of Operational Research, 225(1): 21-35.

Herroelen, W., ve Leus, R. (2004) "Robust and Reactive Project Scheduling: A Review and Classification of Procedures", International Journal of Production Research, 42(8): 1599-1620.

Huang, D., Zhu, S., Fabozzi, F. J., ve Fukushima, M. (2010) "Portfolio Selection under Distributional Uncertainty: A Relative Robust CVaR Approach", European Journal of Operational Research, 203(1): 185-194.

Kang, D., ve Lansey, K. (2012) "Scenario-Based Robust Optimization of Regional Water and Wastewater Infrastructure", Journal of Water Resources Planning and Management, 139(3): 325-338.

Kasperski, A., ve ZielińSki, P. (2006) "The Robust Shortest Path Problem in Series-Parallel Multidigraphs with Interval Data", Operations Research Letters, 34(1): 69-76.

Klabjan, D., Simchi-Levi, D. ve Sang, M. (2013) "Robust Stochastic Lot-Sizing by Means of Histograms", Production and Operations Management, 22 (3): 691-710.

Koster, A. M., Kutschka, M., ve Raack, C. (2013) "Robust Network Design: Formulations, Valid Inequalities, and Computations", Networks, 61(2): 128-149.

Kouvelis, P. ve Yu, G. (1997) Robust Discrete Optimization and Its Applications, USA: Springer.

Lai, K. K., ve Ng, W. L. (2005) “A Stochastic Approach to Hotel Revenue Optimization”, Computers \& Operations Research, 32(5): 1059-1072.

Lan, Y., Gao, H., Ball, M. O., ve Karaesmen, I. (2008) "Revenue Management with Limited Demand Information", Management Science, 54(9): 1594-1609.

Latifoğlu, Ç., Belotti, P., ve Snyder, L. V. (2013) "Models for Production Planning under Power Interruptions", Naval Research Logistics (NRL), 60(5): 413-431.

Lee, C., Lee, K., ve Park, S. (2012) "Robust Vehicle Routing Problem with Deadlines and Travel Time/Demand Uncertainty”, Journal of the Operational Research Society, 63(9): 1294-1306. 
Leung, S.C. ve Wu, Y. (2004). "A Robust Optimization Model for Stochastic Aggregate Production Planning", Production Planning\&Control: The Management of Operations. 15(5): 502-514.

Leung, S.C. ve Wu, Y. (2007) "A Robust Optimization Model for Stochastic Aggregate Production Planning", Production Planning\&Control: The Management of Operation, 15(5): 502-514.

Leung, S.C.H, Tsang, S.O.S., Ng, W.L. Ve Wu, Y. (2007) “A Robust Optimization Model for Multi-Site Production Planning Problem in an Uncertain Environment”, European Journal of Operational Research, 181: 224-238.

Li, Z., Ding, R. ve Floudas, C.A. (2011) "A Comparative Theoritical and Computational Study on Robust Counterpart Optimization: I. Robust Linear Optimization and Robust Mixed Integer Linear Optimization", Industrial \& Engineering Chemistry Research, 50: 10567-10603.

Minoux, M. (2009) "Robust Linear Programming with Right-Hand-Side Uncertainty: Duality and Applications", Encyclopedia of Optimization (ss. 3317-3327), Springer-Verlag.

Mirzapour Al-e Hashem, S.M.J., Maleky, H. Ve Aryanezhad, M.B. (2011) "A Multi Objective Robust Optimization Model for Multi Product Multi-Site Aggregate Production Planning in a Supply Chain Under Uncertainty", International Journal of Production Economics, 134: 28-42.

Moazeni, S., Coleman, T. F., ve Li, Y. (2013) "Regularized Robust Optimization: the Optimal Portfolio Execution Case", Computational Optimization and Applications, 55(2): 341-377.

Moon, Y., ve Yao, T. (2011) “A Robust Mean Absolute Deviation Model for Portfolio Optimization”, Computers \& Operations Research, 38(9): 1251-1258.

Mula, J., Poler, R., Garcia-Sabater, J. P. ve lario, F. C. (2006). Models for Production Planning Under Uncertainty: A Review. International Journal of Production Economics. 103: 271-285.

Mulvey, J. M., Vanderbei, R. J. ve Zenios, S. A. (1995) "Robust Optimization of Large Scale Systems", Operations Research, 43(2): 264-281.

Pascoal, M. M., ve Resende, M. (2014) "The Minmax Regret Robust Shortest Path Problem in a Finite Multi-Scenario Model”, Applied Mathematics and Computation, 241: 88-111.

Perakis, G., ve Sood, A. (2006) "Competitive Multi-Period Pricing for Perishable Products: A Robust Optimization Approach", Mathematical Programming, 107(1-2): 295-335.

Raa, B., ve Aghezzaf, E. H. (2005) "A Robust Dynamic Planning Strategy for Lot-Sizing Problems with Stochastic Demands", Journal of Intelligent Manufacturing, 16(2): 207-213.

Sim, M. (2004) Robust Optimization (Yayınlanmamış Doktora Tezi), Sloan School of Management Massachusetts Institute of Technology.

Sitompul, C., ve Aghezzaf, E. H. (2008) "Robust Production Planning: An Alternative to Scenario-Based Optimization Models", Modelling, Computation and Optimization in Information Systems and Management Sciences (ss. 328-337), Springer Berlin Heidelberg.

Soyster, L.A. (1973) "Convex Programming with Set-Inclusive Constraints and Applications to Inexact Linear Programming", Operations Research, 21(5): 1154-1157.

Sungur, I., Ordónez, F., ve Dessouky, M. (2008) "A Robust Optimization Approach for the Capacitated Vehicle Routing Problem with Demand Uncertainty”, IIE Transactions, 40(5): 509-523.

Thiele, A. (2004) A Robust Optimization Approach to Supply Chains and Revenue Management. (Yayınlanmamış Doktora Tezi), Massachusetts Institute of Technology.

Wiesemann, W., Kuhn, D., ve Rustem, B. (2012) "Robust Resource Allocations in Temporal Networks", Mathematical Programming, 135(1-2): 437-471.

Yamashita, D. S., Armentano, V. A., ve Laguna, M. (2007) "Robust Optimization Models for Project Scheduling with Resource Availability Cost”, Journal of Scheduling, 10(1): 67-76.

Yu, C-S. ve Li, H-L. (2000) “A Robust Optimization Model for Stochastic Logistic Problems”, International Journal of Production Economics, 64: 385-397.

Zanjani, M.K., Ait-Kadi, D. Ve Nourelfath, M.(2010) "Robust Production Planning in a Manufacturing Environment with Random Yield: A Case in Sawmill Production Planning", European Journal of Operational Research, 201: 882891.

Zhou, Zhili. (2010) "Multi-Stage Discrete Optimization under Uncertainty and Lot Sizing”, (Yayınlanmamış Doktora Tezi). Florida Üniversitesi. 